\title{
Attentional switching in humans and flies: rivalry in large and miniature brains
}

\author{
Steven Mark Miller ${ }^{1}{ }^{*}$, Trung Thanh $_{\text {Ngo }}{ }^{1}$ and Bruno van Swinderen ${ }^{2}$ \\ 1 Perceptual and Clinical Neuroscience Group, Monash Alfred Psychiatry Research Centre, Central Clinical School, Monash University, Melbourne, VIC, Australia \\ 2 Queensland Brain Institute, The University of Queensland, Brisbane, QLD, Australia
}

\author{
Edited by: \\ Naotsugu Tsuchiya, RIKEN, Japan \\ Reviewed by: \\ Tomas Knapen, University of \\ Amsterdam, Netherlands \\ Mikko Juusola, University of \\ Sheffield, UK

\section{*Correspondence:} \\ Steven Mark Miller, Monash Alfred \\ Psychiatry Research Centre, Level 1, \\ Old Baker Building, Baker Lane, The \\ Alfred, Melbourne, VIC 3004, \\ Australia. \\ e-mail: steven.miller@monash.edu
}

\begin{abstract}
Human perception, and consequently behavior, is driven by attention dynamics. In the special case of rivalry, where attention alternates between competing percepts, such dynamics can be measured and their determinants investigated. A recent study in the fruit fly, Drosophila melanogaster, now shows that the origins of attentional rivalry may be quite ancient. Furthermore, individual variation exists in the rate of attentional rivalry in both humans and flies, and in humans this is under substantial genetic influence. In the pathophysiological realm, slowing of rivalry rate is associated with the heritable psychiatric condition, bipolar disorder. Fly rivalry may therefore prove a powerful model to examine genetic and molecular influences on rivalry rate, and may even shed light on human cognitive and behavioral dysfunction.
\end{abstract}

Keywords: binocular rivalry, ambiguous figure, Drosophila, attention, switch rate, bipolar disorder, individual variation, endophenotype

\section{INTRODUCTION}

Perceptual rivalry amuses and intrigues those who experience it and those who study it. Though it has many faces, the phenomenon is defined fundamentally by conflicting or ambiguous sensory input that induces involuntary alternations in perception. Famous examples include ambiguous figure rivalry (AFR) such as the Necker cube (Figure 1A) and Rubin's vase-faces illusion (Figure 1B), which cause perspective reversals and figureground reversals, respectively, and are elicited under normal (dioptic) viewing conditions (Long and Toppino, 2004). Under dichoptic viewing conditions, in which stimuli are presented separately to each eye, perceptual alternations also arise if the stimulus features are sufficiently incongruent - a phenomenon known as binocular rivalry (BR; Figure 1C; Blake and Logothetis, 2002; Alais, 2012; Howard and Rogers, 2012; Miller, forthcoming).

For more than 100 years, AFR and BR have been characterized and probed in the hope of eventually understanding neurophysiological mechanisms underlying the perceptual alternations (e.g., McDougall, 1906). In the last 20 years, psychophysical methods have merged with modern neuroscientific methods and there is now widespread, concerted effort to reach the goal of this mechanistic understanding. Along the way, a multitude of new rivalry types have been described and incorporated into the pursuit, and promising new research directions have emerged.

\section{CLINICAL, GENETIC, AND MOLECULAR APPROACHES TO PERCEPTUAL RIVALRY}

One such new direction stems from recent reports that the rate of $\mathrm{BR}$ is slow in the psychiatric condition, bipolar disorder (BD; manic depression; Pettigrew and Miller, 1998; Miller et al., 2003). Factors affecting switch rate during perceptual rivalry have long been studied using both AFR and BR. Indeed, in both rivalry types, the similar effects on switch rate of varying such factors has been used to argue, along with a range of other evidence, that AFR and BR share at least some degree of common mechanism (e.g., Leopold and Logothetis, 1999; Ngo et al., 2008). In the case of BR, modifying the level of stimulus salience or "stimulus strength" is well known to affect the rate of alternation between the presented images. Thus, observers presented with stimuli that are moving, of high contrast, and of high spatial frequency, will switch faster than when presented with stationary, low contrast, low spatial frequency stimuli (Howard and Rogers, 2012). Similar findings regarding stimulus properties and switch rate have been shown with AFR (e.g., Long and Toppino, 2004).

Another feature both types of rivalry share is that switch rate between individuals exhibits wide variation, but within an individual is highly reliable (e.g., McDougall, 1906; Ewen, 1931; George, 1936; Enoksson, 1963; Aafjes et al., 1966; Borsellino et al., 1972; Pettigrew and Miller, 1998; Miller et al., 2010). Although individual variation in perceptual rivalry rate was a topic of interest in the early-mid twentieth century (e.g., Frederiksen and Guilford, 1934; Crain, 1961), the search for rivalry mechanisms in the late twentieth century led instead to individual differences being considered a distraction. However, just as the pendulum has swung historically between low- and high-level mechanistic explanations of rivalry (Blake, 2001), so too it appears to be swinging back toward the field's interest in individual differences. With psychophysicists having well characterized extrinsic (stimulus and presentation) features affecting rivalry rate, the search is now on to determine intrinsic (endogenous) determinants of individual variation in switch rate (Miller et al., 2010). This renewed interest in individual differences began with the serendipitous finding in the late 1990s that the rate of BR is slow in BD (Pettigrew and Miller, 1998). Not surprisingly however, given proposals for common mechanisms of BR and AFR, similar reports of slow AFR rate in BD had been 
published in the early twentieth century (Ewen, 1931; Hunt and Guilford, 1933).

Bipolar disorder is characterized by episodes of mania and depression, most often with periods of euthymia (normal mood) in between. The condition, when diagnosed accurately, is usually amenable to control with appropriate medication but can also be devastating to individuals who fail to take such medication or who become refractory to it. There are two main types of $\mathrm{BD}$, the severe form (BD-I; diagnosis of which requires the individual having been admitted to hospital with a manic episode), and a less severe form (BD-II; which involves only hypomanic episodes, without hospital admission). Current psychiatric classification (American Psychiatric Association, 2000) also provides for additional related diagnoses such as cyclothymia and BD-not otherwise specified. In the initial report of slow BR in BD (Pettigrew and Miller, 1998), using high-strength stimuli (drifting gratings of high spatial frequency), control subjects showed perceptual switches on average every 1-2 s, whereas subjects with BD-I switched, on average, every 3-4 s, with some perceptual periods lasting as long as 7-10 s.

This finding was confirmed in a subsequent study, using lower strength stimuli (Miller et al., 2003), though group separation was less in this second study. Together however, the two studies suggested that slow BR rate could distinguish BD-I $(n=50)$ from controls $(n=93)$ with a sensitivity of approximately $80 \%$ (requiring confirmation with larger datasets). The second study also reported that (i) BR rate in BD-I $(n=30)$ was significantly slower than that in schizophrenia (SCZ; $n=18$ ) and in major depressive disorder (MDD; $n=18$ ), and (ii) BR rate in SCZ and MDD was not significantly different from that of controls $(n=30)$. The findings for SCZ and MDD, though preliminary, suggested that specificity of the slow BR rate trait for BD-I may also be of the order of $80 \%$ (again requiring confirmation with larger datasets).

There have since been two independent replication studies, one using an ambiguous structure-from-motion stimulus (Krug et al., 2008) and another using BR (Nagamine et al., 2009), with both confirming significantly slower perceptual rivalry rate in BD-I compared with controls. The study by Nagamine et al. (2009) also found that BR rate in BD-II was not significantly different from that in controls. Nagamine et al. (2009) used BR stimuli of intermediate strength, while Krug et al. (2008) used an ambiguous structure-from-motion stimulus that was of very low strength (inducing switches in $\mathrm{BD}$ subjects and controls of the order of tens of seconds). Although switch rate was significantly slower in BD-I subjects than in controls in both studies, the differences found between groups were less than in earlier work using highstrength BR stimuli (Pettigrew and Miller, 1998). One explanation for the group separation differences found between studies is that high-strength stimuli provide better discriminative separation of BD subjects from controls (and by extension, from other clinical groups; Miller et al., 2003; Ngo et al., 2011). However, further work varying stimulus strength parameters within the same control and clinical subjects is required to verify this proposal. The available BR rate data (with corresponding stimulus strengths indicated) are presented in Figure 2.

Bipolar disorder is highly heritable (Smoller and Finn, 2003; Lichtenstein et al., 2009) and reports of a slow BR rate associated with this condition have raised the prospect of using this trait as a biological marker (or "endophenotype") for the disorder. Misdiagnosis is common in clinical psychiatry, especially between (i) the psychosis of SCZ and that due to BD, and (ii) the depression of MDD and that due to BD (Joyce, 1984; Conus and McGorry, 2002). Such misdiagnosis has important implications because treatment decisions differ according to diagnosis. A biological marker that is sufficiently sensitive and specific to improve diagnosis in these contexts would have major treatment implications. Indeed, there are no diagnostic tests in clinical psychiatry. Slow BR rate is currently being explored regarding this potential diagnostic application (Ngo et al., 2011).

In addition to potential clinical diagnostic utility, biological markers can be explored as endophenotypes for heritable conditions, wherein the biomarker represents an "intermediate phenotype" that marks an underlying at-risk genotype. This marking occurs even though the clinical phenotype - the psychiatric disorder - may not have yet manifested (or indeed may never manifest). Such markers would have important preventive implications for relatives of individuals with $\mathrm{BD}$, some of whom inherit the atrisk genotype, and some of whom do not. Indeed, the strategy of endophenotype identification is now acknowledged within psychiatric genetics (Gottesman and Gould, 2003) as an important approach to dealing with clinical heterogeneity of psychiatric disorders (the cause of the diagnostic difficulties). Because genomewide association studies (GWAS) of psychiatric disorders (which aim to identify predisposing genes) depend on accurate clinical diagnosis, endophenotypes can thus be used in place of reliance

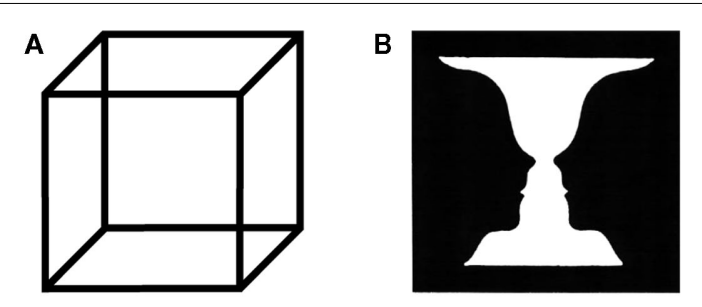

c PRESENTED

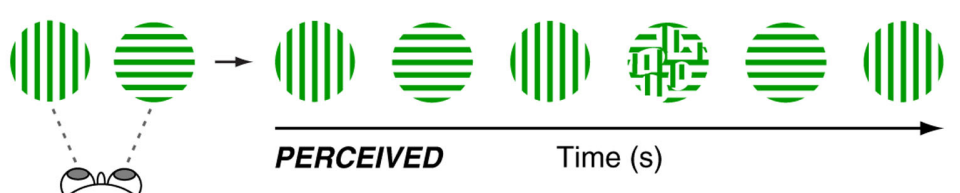

FIGURE 1 | (A) The Necker cube is a well known two-dimensional image that when viewed is perceived to alternate between two different depth perspectives. (B) Rubin's vase-faces illusion alternates between figure and ground. (C) To elicit binocular rivalry, two dissimilar

images are presented, one to each eye. The observer alternates between perceiving one image for a few seconds, followed by the other image for a few seconds and so on (with occasional short periods of mixed percepts). 


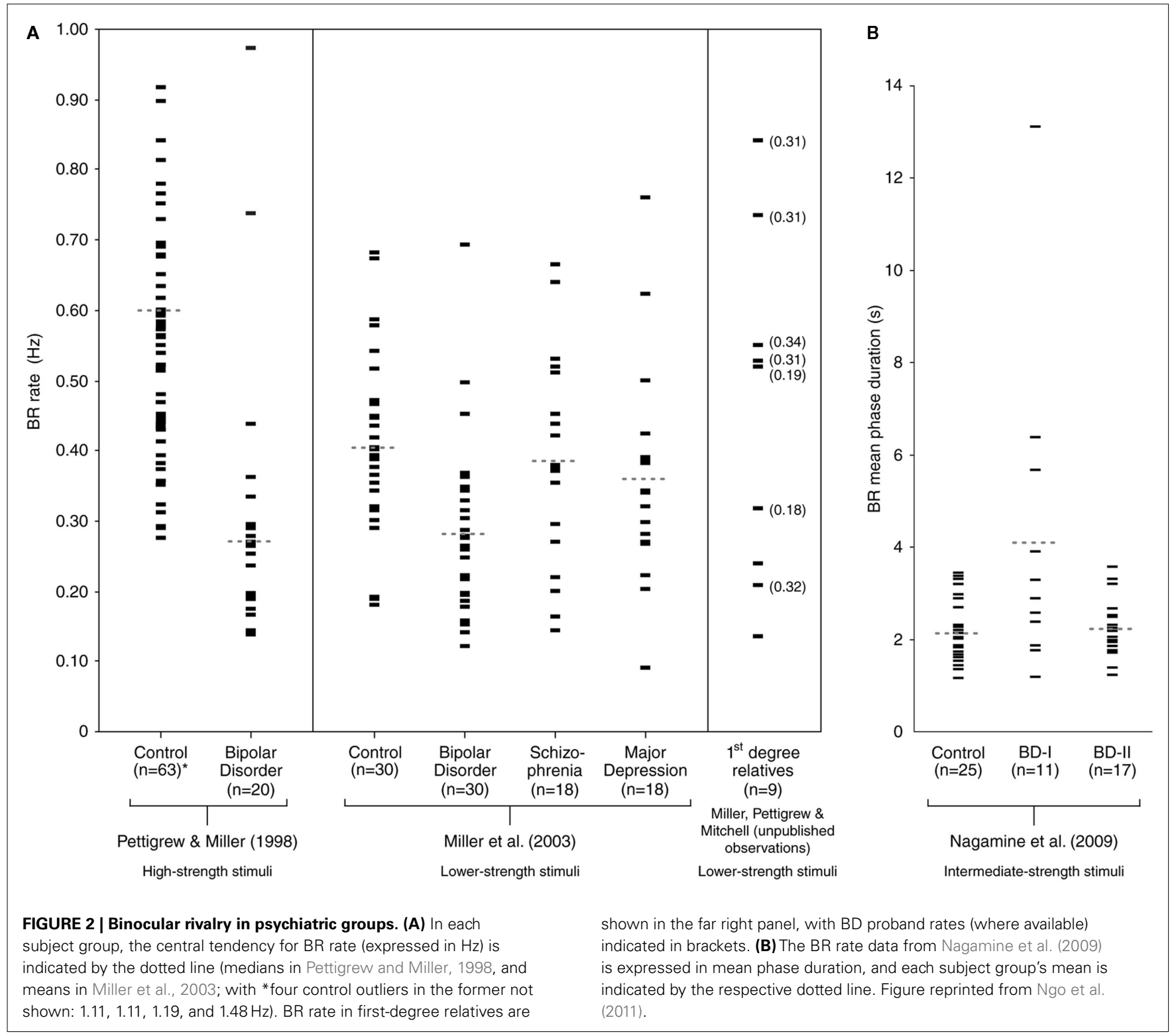

on clinical diagnosis. This approach acts to increase the statistical power of such studies by more accurately classifying "affected" versus "unaffected" prior to genetic analyses. For this potential application too, slow BR rate is currently under investigation (Ngo et al., 2011).

The key criteria required for a trait to satisfy endophenotype status for heritable disorders (Gottesman and Gould, 2003; Kendler and Neale, 2010) include that it is: (i) associated with the condition (i.e., sensitive), (ii) heritable, (iii) reliable, (iv) unaffected by clinical state, (v) co-segregated with illness in families, and (vi) found in first-degree relatives more commonly than in the general population. Sensitivity of slow BR rate for BD has been discussed above. Heritability and reliability of BR rate were recently examined in a large-scale, 10-year study of normal monozygotic and dizygotic twins, aged 14 years $(n=722), 97$ of whom were re-tested after 2 years (Miller et al., 2010; see Figure 3). Using high-strength stimuli, substantial genetic contribution to individual variation in
BR rate was found, with the best-fitting model attributing 52\% of the variance to additive genetic factors. The study also confirmed, with a large dataset, that $\mathrm{BR}$ rate is highly reliable within $(R=0.93)$ and between $(R=0.70)$ testing sessions. In a recent small twin heritability study, high monozygotic, but not dizygotic, twin concordance was confirmed for BR rate, and reported for Necker cube switch rate (Shannon et al., 2011).

With respect to the remaining endophenotype criteria, currently there are insufficient data on $\mathrm{BR}$ rate in relatives of $\mathrm{BD}$ probands to yet claim genetic correlation between slow BR rate and BD, but early data are promising (Ngo et al., 2011). Effects of clinical state in $\mathrm{BD}$ - i.e., mania, depression, euthymia - on $\mathrm{BR}$ rate remain to be clarified, however slow $\mathrm{BR}$ rate is evident in euthymic BD subjects (Ngo et al., 2011). Similarly, medication effects cannot yet be excluded, but do not appear to account for the trait (Ngo et al., 2011). Definitive assessment of state and medication effects requires BR rate measurement before and after state 

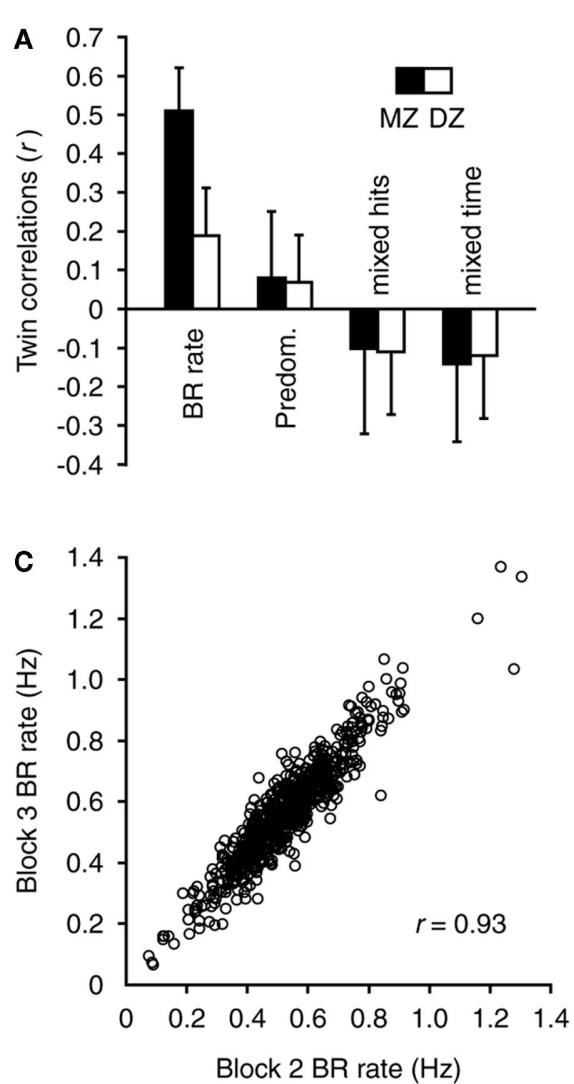

FIGURE 3 | Heritability and reliability of BR rate. These four panels show the population BR and genetic modeling data from a sample of 722 twins (Miller et al., 2010). (A) Twin correlations for BR measures in $\mathrm{MZ}$ and DZ twins (error bars indicate 95\% confidence intervals). Correlations for BR rate were significant. Correlations for predominance (i.e., the amount of time spent perceiving one image relative to the other) and for mixed hits/time (i.e., number of, and time associated with, mixed percepts, or incorrect responses) were found to be not

and medication change in clinical subjects. Medication effects can also be addressed by way of pharmacological challenge studies in healthy controls (see below).

In addition, two factors that may affect BR rate and that are relevant in psychiatric populations are reaction time and eye movements. However, in the twin heritability study of BR rate (Miller et al., 2010), processing speed measures were not related to $\mathrm{BR}$ rate (additional publication in preparation), thereby eliminating reaction time differences as an explanation for individual variation in BR rate (see also Nagamine et al., 2009). Regarding eye movements, in the context of BR these are not thought to be the cause of perceptual switches, but do have an influence (with saccade frequency being positively correlated with BR rate; van Dam and van Ee, 2006). However, studies of eye-movement profiles in BD generally show no saccade frequency anomalies during smooth pursuit tasks (Martin et al., 2007). Hence, differences in eye-movement profiles are also considered unlikely to account for slow BR rate in BD. Nonetheless, a potential effect of eye movements on BR rate in clinical psychiatric groups cannot yet be excluded and remains to be directly assessed.
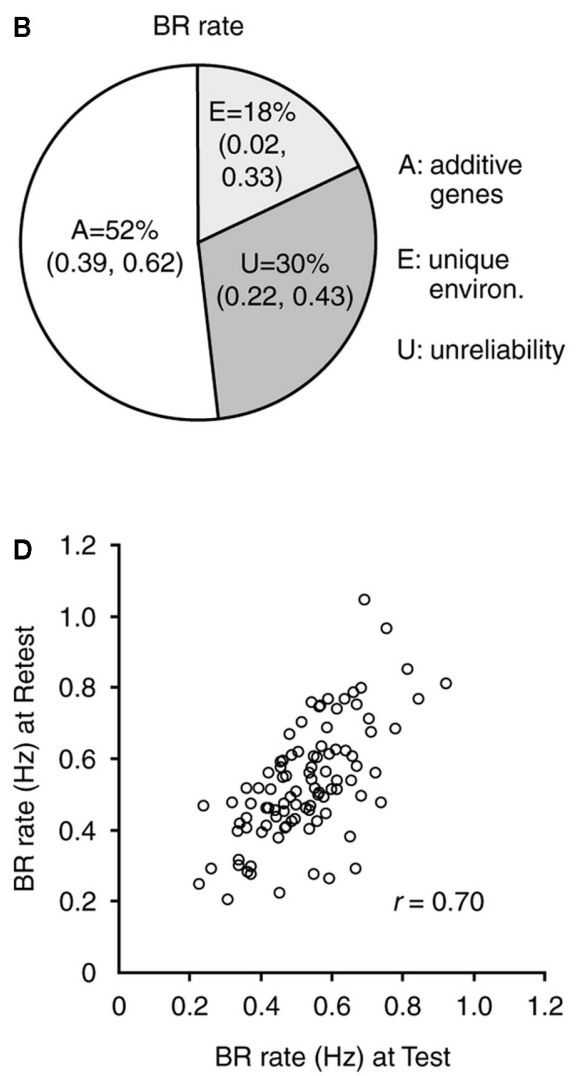

significant and therefore were not included in genetic modeling analyses. (B) The genetic modeling results indicate that the variance in $B R$ rate was because of a substantial additive genetic component; plus unique environment and measurement unreliability over a period of

2 years. (C) Reliability of BR rate within a testing session was very high $(n=722)$. Note also the high degree of $B R$ rate individual variation in this large dataset. (D) Reliability of BR rate was also high between testing sessions 2 years apart ( $n=97)$. Figure reprinted from Miller et al. (2010).

In pharmacological studies, alcohol and caffeine decrease and increase, respectively, both AFR and BR switch rate (George, 1936; Seedorff, 1956). These agents similarly affect AFR rate in subjects with SCZ or BD (Ewen, 1931). More recently, pharmacological studies have been applied in healthy controls, and have shown that $\mathrm{BR}$ rate decreases in the presence of serotonin agonists, with the serotonin receptor subtype $5-\mathrm{HT}_{1 \mathrm{~A}}$ implicated in mediating this effect (Nagamine et al., 2008). However, $5-\mathrm{HT}_{2 \mathrm{~A}}$ may also play a role (Carter et al., 2005) and it remains unclear at what site in the brain - from raphe nucleus in the brainstem, to limbic regions, to visual cortex - such effects are exerted (Nagamine et al., 2008). Noradrenergic pathways also appear to be involved in AFR and other rivalry types (Einhäuser et al., 2008). These reports suggest targets for candidate gene studies (in addition to GWAS) that could be undertaken to examine molecular mediators of individual variation in perceptual rivalry rate (e.g., Kondo et al., in press).

The findings of slow BR rate in $\mathrm{BD}$ and of substantial genetic contribution to individual variation in $\mathrm{BR}$ rate, suggest that the stage is now set for vigorous pursuit of genetic and molecular determinants of rivalry switch rate. Moreover, in light of this new 
direction in perceptual rivalry research, an animal model of the phenomenon that could readily enable genetic and pharmacological manipulation of switch rate would be highly advantageous. As it turns out, one such model has been recently reported for Drosophila melanogaster (Tang and Juusola, 2010). Moreover, the Drosophila model is also (i) amenable to direct mechanistic examination, and (ii) beginning to be understood at the level of attentional selection and suppression.

\section{PERCEPTUAL RIVALRY AND ATTENTION}

Attention can be as difficult to describe as it is easy to understand intuitively. Attention describes our ability to focus our perception on one stimulus (or group of related stimuli), while filtering out other simultaneous stimuli that are less relevant at any moment (Posner et al., 1980). The relevance of a stimulus is dependent on its salience, and salience itself clearly depends on the history of events as well as on the physical features of the stimulus. To better segregate these distinct contributions to salience, attention is often conveniently compartmentalized as "bottom up" (guided by the physical stimulus only, e.g., loudness or brightness), or "top down" (guided by past experience; Treisman and Gelade, 1980; Itti and Koch, 2000). However, a more fundamental feature of any attention process is that it involves suppression. Attention is often viewed as a "spotlight" (LaBerge, 1983; Eriksen and St James, 1986), perhaps because that is how the process feels to our conscious minds. However, to identify and measure attention-like processes in animals - any animal from flies to apes - requires some evidence of suppressed responsiveness to competing stimuli (Van Swinderen, 2005). Otherwise, an animal's choice can always be argued to be a simple reflex, much like bacteria swimming up a chemical gradient, rather than a cognitive process where most stimuli were blocked from having a behavioral consequence and only one or a few not blocked. The role of suppression mechanisms in the evolution of animals is evident: to make effective connections between stimuli - to learn - requires blocking out the contexts, or the multitude of stimuli that have less predictive value, regardless of how salient they may be. To understand how salient stimuli are prevented from producing a behavioral response in animals seems just as important for any study of attention as is the more anthropocentric notion of a spotlight.

How can stimulus suppression be identified and measured in simple animals such as flies? The simplest way to do this is by studying sleep, and the decreased behavioral responsiveness associated with this altered arousal state. The discovery a decade ago that flies sleep (Hendricks et al., 2000; Shaw et al., 2000) suggested a broader role for stimulus suppression mechanisms, perhaps also relevant to attention-like processes in these simple animals - which were identified soon thereafter (Van Swinderen and Greenspan, 2003; Van Swinderen, 2007a). The special case of perceptual rivalry presents exactly the kind of stimulus conditions that, if identified in a genetic model such as Drosophila melanogaster, would allow one to investigate how an animal suppresses responsiveness to one salient stimulus while responding to another. By reducing the attention problem in the Drosophila model to two equally salient choices, selection and suppression dynamics might be more easily studied and possible underlying mechanisms unraveled. Before putting forward the case for attention and rivalry in flies, we first review the connection between these related phenomena in humans.

Binocular rivalry has been long considered in terms of attention, with respect to notions of both voluntary and involuntary attention (Von Helmholtz, 1867; James, 1890; Sherrington, 1906). It is well known that BR and AFR predominance and switch rate are subject to some degree of voluntary control, though such modulation is modest (especially for BR) and the perceptual switches cannot be prevented (Wheatstone, 1852; Von Helmholtz, 1867; Breese, 1899; Lack, 1978). In support of high-level theories of the phenomenon, semantic content in presented stimuli can also influence percept dominance (Walker, 1978). Moreover, during $\mathrm{BR}$ and AFR, engaging in a concurrent attentional task has been shown to influence the rate of perceptual alternations (Wallace and Priebe, 1985; Paffen et al., 2006; Alais et al., 2010). Investigators have also previously highlighted the overlap between rivalry and selective attention in regard to both cortical areas and mechanisms involved (Logothetis, 1998; Lumer et al., 1998; Leopold and Logothetis, 1999; Stoner et al., 2005). Other psychophysical studies have shown that voluntary attention facilitates the induction and maintenance of perceptual dominance of a spatially cued target image (Ooi and He, 1999; Chong and Blake, 2006; Hancock and Andrews, 2007), while involuntary attention also facilitates induction of dominance in this selective attention paradigm (Mitchell et al., 2004; Chong and Blake, 2006; Hancock and Andrews, 2007; Kamphuisen et al., 2007). The psychophysical evidence therefore argues for a strong modulatory role of attentional selection in BR.

Just as notions of attentional selection have contributed to theorizing about rivalry, so too have notions of suppression. In contrast to the high-level attentional explanations of rivalry discussed above, an earlier body of work by Fox, Blake and colleagues favored a low-level explanation of the phenomenon. This view was based largely on the finding of reduced sensitivity to detection of test probes presented whilst a stimulus was suppressed compared with while the stimulus was visible, even though the probe's stimulus features were different to those of the suppressed stimulus (Fox and Check, 1968, 1972; Wales and Fox, 1970). This finding suggested perceptual suppression during BR was non-selective (i.e., not limited to particular features of the suppressed stimulus) and led to a low-level neural theory of BR (Blake, 1989). Other psychophysical and brain-imaging studies have also led theorists to suggest that the neural mechanisms underlying dominance (selection) during rivalry may be distinct from those underlying suppression (Logothetis, 1998; Blake, 2001; Blake and Logothetis, 2002). More recently, brain-imaging studies and new dichoptic presentation paradigms (continuous flash suppression; Tsuchiya and Koch, 2005) have been employed to further examine the neural basis of rivalrous perceptual suppression (Lin and He, 2009).

Around the time that notions of attention were applied to BR (Von Helmholtz, 1867), other scholars noted that perceptual rivalry could also occur in non-visual modalities, such as olfaction and audition (Valentin, 1844; Fechner, 1860). Recently, similarities and differences between rivalry in visual and non-visual domains have been examined. For example, perceptual switches in both auditory and visual rivalry types (including AFR) were found to be associated with pupil dilation (Einhäuser et al., 2008; cf. Hupé et al., 2009). Others have found a lack of correlation between the 
temporal properties of rivalry (including rate and predominance) in different modalities within individuals (Pressnitzer and Hupé, 2006; Carter et al., 2008), though Hupé et al. (2008) did show an association between auditory and visual rivalry rates within individuals. However, the temporal dynamics of simultaneous presentation of these rivalry types revealed limited crossmodal interactions (e.g., a brief effect of crossmodal congruence on perceptual dominance), which these investigators argued was evidence for a distributed processing account of perceptual disambiguation, over a central supramodal mechanism.

Several other studies though, have argued for multisensory and attentional processing in BR, based on the following findings: directional sound increases perceptual dominance of a directionally congruent motion stimulus (Conrad et al., 2010); tactile stimulation increases perceptual dominance and reduces suppression of a congruent grating orientation (Lunghi et al., 2010); increased perceptual dominance and reduced suppression of a moving stimulus that was congruent with an individual's hand movement direction (Maruya et al., 2007); voluntary attention to non-visual congruent stimuli (auditory and/or tactile) enhances attentional control of visual dominance (van Ee et al., 2009); and an olfactory stimulus increases dominance and decreases suppression of a visually congruent image (Zhou et al., 2010). These findings therefore raise the possibility of a supramodal attentional mechanism that resolves conflicting sensory input during rivalry.

Further evidence for the role of attention in BR comes from brain stimulation studies in which activation of attentional structures modulates predominance during BR and AFR (Miller et al., 2000; Ngo et al., 2007, 2008), and from recent EEG and fMRI studies (Watanabe et al., 2011; Zhang et al., 2011). In the next section, we maintain focus on the visual domain and examine the evidence for attention and rivalry in a miniature brain.

\section{ATTENTIONAL SWITCHING AND PERCEPTUAL RIVALRY IN DROSOPHILA MELANOGASTER}

It comes as a surprise for some people to learn that flies have a brain. Until quite recently, the fruit fly was not considered a useful model for investigating higher-order cognitive phenomena such as selective attention, let alone perceptual rivalry. Rather, a century of work had already proven that Drosophila melanogaster was an excellent model for unraveling fundamental biological processes, such as gene regulation or development (for an excellent recent review on Drosophila applications and relevance to neuroscience, see Bellen et al., 2010). Although the anatomy of human and fly brains is in many respects substantially different (e.g., 100 billion versus 200,000 neurons in each animal, respectively), there are some organizational similarities (e.g., the fly brain is also largely divided across the midline) and the neuronal processes and molecules involved are remarkably similar in each case. For example, dopamine and serotonin control arousal states in both flies and humans (Van Swinderen and Andretic, 2011). For a complex phenomenon such as rivalry, the difference in neuroanatomy between flies and humans can be turned to an advantage: if both creatures display perceptual alternations via a substantially different neuroanatomy, then mechanistic comparisons between both species should highlight the fundamental requirements for rivalry, rather than the structures that may have co-evolved with rivalry in one animal alone. Thus, fly-human comparisons are also extremely valuable for understanding common phenomena, such as sleep and attention. A brief overview of Drosophila behavior genetics will highlight how the vinegar fly was promoted from humble beginnings to its growing status alongside human psychiatric research (for a more extensive review on using Drosophila for neuropsychiatric research, see O'Kane, 2011).

Behavior can be genetically dissected, much like any physical phenotype. A revolutionary approach by Seymour Benzer and colleagues in the 1960s saw Drosophila genetic methods being applied to behavior (Hotta and Benzer, 1970). Indeed, researchers soon found Drosophila to be an ideal organism for dissecting the genetic underpinnings of various behaviors: one could screen for mutants, much like with viruses or bacteria, but in an animal endowed with a brain. The first behavioral screens were the simplest: responsiveness to light, seemingly a simple reflex, was found to be variable among populations of flies, and odd mutants such as photophobia (which ran away from light) were among the first genetic manipulations of behavior in flies (Benzer, 1967). Combined with parallel advances in molecular genetics, the genes causing the behavioral effects could be identified, and cellular/molecular pathways controlling these behaviors could be understood. Among the many triumphs resulting from this approach to dissecting behavior, two stand out: circadian rhythms and memory formation (for a review, see Vosshall, 2007). While we now know much about the cellular and molecular underpinnings of learning/memory and circadian rhythms in flies, we know far less about how the fly brain actually controls behavioral choices made by the animal. In part, this is because Drosophila studies have mostly measured behavior as a probabilistic variable, where the outcome of a population determines the phenotype that is being associated with gene effects. Indeed, when examined at a population level, flies behave probabilistically (Quinn et al., 1974). But any fly behaviorist will admit that, when examined individually, their flies display idiosyncrasies, much like humans do. Even Seymour Benzer, who pioneered population approaches to dissecting fly behavior, noted that "an individual fly will make its own decision." The highly successful strategy of studying fly behavior at a population level has been less useful for understanding decision-making in flies, or whether perceptual rivalry might exist in this simple animal. Another paradigm, the flight arena, would prove most insightful in this regard.

When humans are engaged in visual psychophysical experiments in a psychology laboratory, they are typically asked to sit still and fixate on a point on a screen while responding to queries about what they see. Responses are either verbal, or via button presses. The Drosophila flight arena presents a quite similar scenario for flies (Figure 4A): individual flies are tethered to a rod while they respond with flight torques to visual stimuli displayed on a rotating drum that surrounds them (Heisenberg and Wolf, 1984; see Brembs, 2008, for a visual explanation of the device). A torque meter attached to the tether measures ongoing behavioral choices (torque spikes to the left or to the right) made by the fly, and negative feedback from the torque meter (termed "closed-loop" mode) can be used for the fly to itself control the angular position of a visual scene displayed on the inside of the drum. More recent designs use wing-beat detectors and virtual displays on LED arenas 
A

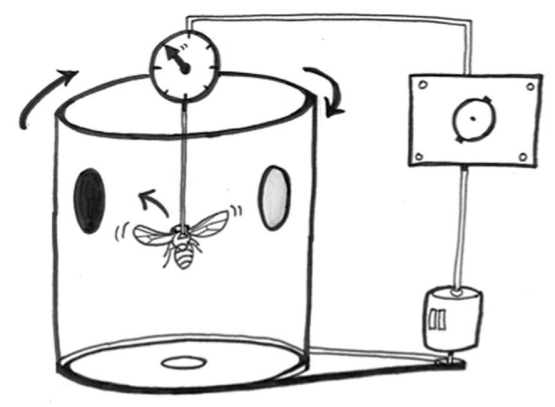

B

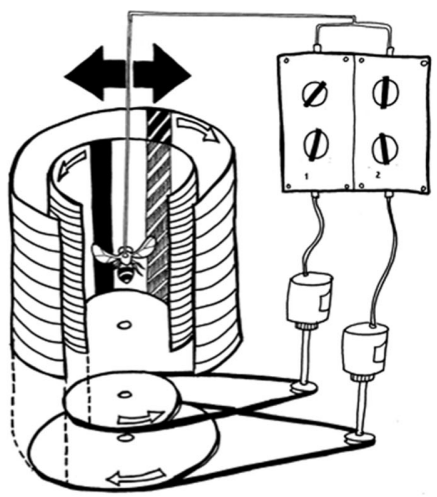

C

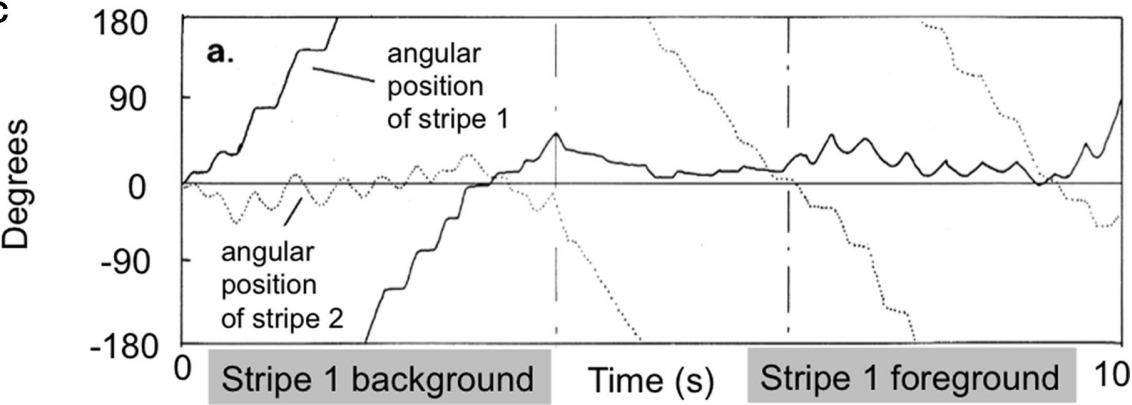

FIGURE 4 | Drosophila flight arena concept and first rivalry experiments. (A) Tethered flies respond to visual stimuli displayed on a drum surrounding them by modulating their flight dynamics. A torque meter measures the flies' left or right turn choices, and negative feedback can be used for the fly to control the angular position of displayed objects. Tethered flies will tend to fixate on objects, by modulating their torque behavior to keep attended objects in front of them. (B) Adding an extra visual layer, as well as a separate control system requiring a distinct behavioral response, allows the fly to fixate on one or the other object separately. (C) An early experiment showing alternating figure-ground selection in flies presented with two competing objects, as in (B). Reprinted with permission, from Heisenberg and Wolf (1984, p. 274). can be used to accomplish the same goal of measuring behavioral responses to visual stimuli in individual flies (Lehmann and Dickinson, 1997; Sareen et al., 2011). It may be somewhat surprising to note that there are few visual paradigms in any animal models that offer such a careful level of control as the Drosophila flight arena: since the animal is tethered, the fly only sees and responds to what is presented to it under a defined set of conditions. By minimizing any visual "contamination" (such as may be generated by the animal's own movement through space), the tethered flight paradigm provides exactly the kind of experimental conditions required for a study of perceptual rivalry. In contrast, a rat (for example) provided with visual choices while running around a cage is less amenable to studies of rivalry, because the experimenter can never be entirely certain of what the animal is seeing at any one time. However, restraining an animal often prevents any behavioral report, presenting a serious dilemma for rivalry studies in animals. Indeed, between head-restrained, lever-operating primates, and tethered flies, there are strikingly few visual perception paradigms conducive to the stringent conditions required for studying rivalry in awake animals.

In the flight arena, a tethered fly will respond to stimuli by turning in the same direction as perceived movement (Heisenberg and Wolf, 1984). This behavior is called an optomotor response, and like the optokinetic responses of humans (e.g., Masseck and Hoffmann, 2009), it is considered a simple reflex that is important for image stabilization and gaze control. Considerable work has been done to describe fly optomotor responses to a variety of visual parameters, and most were documented in the early 1980s by Martin Heisenberg and Reinhard Wolf in their "little green book" on vision in Drosophila (Heisenberg and Wolf, 1984). Careful reading of that seminal work will reveal the first experiments suggesting perceptual rivalry in flies (e.g., pp. 174-175). Instead of presenting flies with just one visual stimulus printed on one layer of the surrounding drum, they presented two objects on separate transparent layers, each moving with a fixed angular velocity relative to one another, and thus each requiring an opposing behavioral response for closed-loop stabilization (Figure 4B). Therefore, if the fly "fixated" on one object (by modulating its torque behavior accordingly), the other would spin wildly, and vice versa for the alternate object. Heisenberg and Wolf (1984) noticed that a fly would often select one object as a "foreground" and the alternate as the "background," by adjusting its optomotor balance to one while stabilizing the other by means of torque spikes. After a period of time, the fly would then switch its behavior and reverse the foreground-background contingency (Figure 4C). Optomotor theory (see Borst et al., 2010, for a review) would suggest that flies adjust their torque to the mean of the two values, resulting in the two objects moving with equal (reduced) speed in opposite directions. Although this outcome did occur too at times (much like the occasional mixed and grid percepts during human rivalry with 
orthogonal gratings), these first closed-loop experiments showed that flies could alternate their behavioral response between two competing percepts presented simultaneously.

Behavioral alternations between competing percepts were also demonstrated in open loop experiments (where the fly cannot control the angular position of objects). In these experiments (Heisenberg and Wolf, 1984, pp. 188-191), flies were presented with two competing vertical stripes, one to either eye (at $45^{\circ}$ to the left or right of a forward-facing direction). The fly was found to be able to adjust its torque behavior to oscillatory movements of either object independently, alternating its behavior between two choices presented bilaterally (Figure 5A). In addition to suggesting that rivalry may also be partitioned between the two hemispheres of the fly brain, these experiments showed that the fly does not require closed-loop control to display perceptual alternations. In this way, behavior during these visual competition experiments resembled selective attention: flies alternately selected or suppressed responses to either object, and this occurred with a defined tempo that seemed variable among individuals. More dedicated follow-up experiments would likely have identified and quantified fly rivalry, and individual variation therein, but this line of research was not pursued at the time. The preparation was exploited instead over the following decades for two other challenges: visual learning (e.g., Wolf and Heisenberg, 1991; Brembs and Heisenberg, 2000) and flight control (e.g., Dickinson et al., 1999; Sherman and Dickinson, 2003).
Evidence for rivalry in flies was found again in a recent study, by combining tethered flight and electrophysiology in Drosophila (Tang and Juusola, 2010). The authors utilized a similar tethered set-up as in the paradigm described above, but instead placed the fly between two moving gratings - one presented to either eye (Figure 5B). Two tiny electrodes recorded local field potential (LFP) and spiking activity from either optic lobe while the fly responded in open loop (i.e., without being able to control the optic flow) to these competing visual stimuli (Figure 5C). The experiment presented a visual conflict similar to Heisenberg and Wolf's (1984) original experiment consisting of two opposing oscillating bars (discussed above). As in some of that original flight arena work, in the current paradigm flies were observed to alternate their flight direction choices between the right and the left moving grating. Again, this was not expected according to optomotor theory: equivalent optic flow presented to either eye should either (i) elicit a landing response (Tammero and Dickinson, 2002), or (ii) produce straight flight as a result of averaged optomotor responses from either eye (Srinivasan et al., 1999). Instead, flies displayed a number of behaviors that were more reminiscent of visual attention than optomotor reflexes: first, left or right flight choices were not made immediately following bilateral image motion, but was often delayed for up to a few seconds. Then, flight behavior was sustained in either direction rather than saccadic, as is more common for classical optomotor responses in a rotating drum (Heisenberg and Wolf, 1984). Third, flies
A

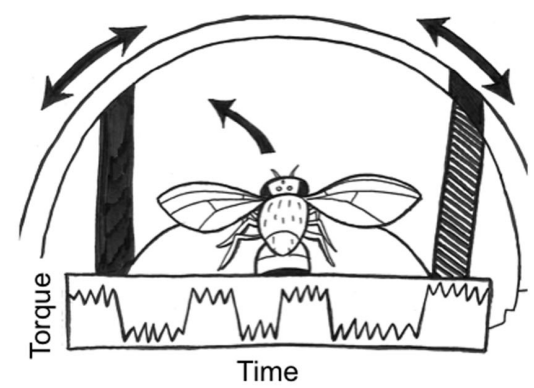

B

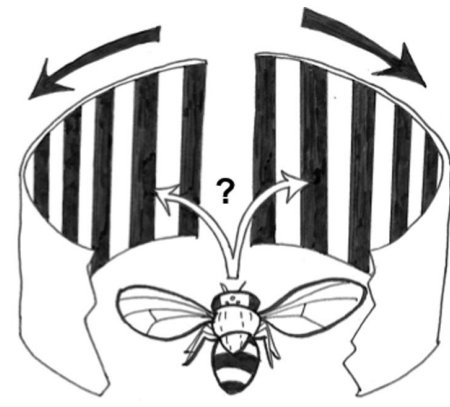

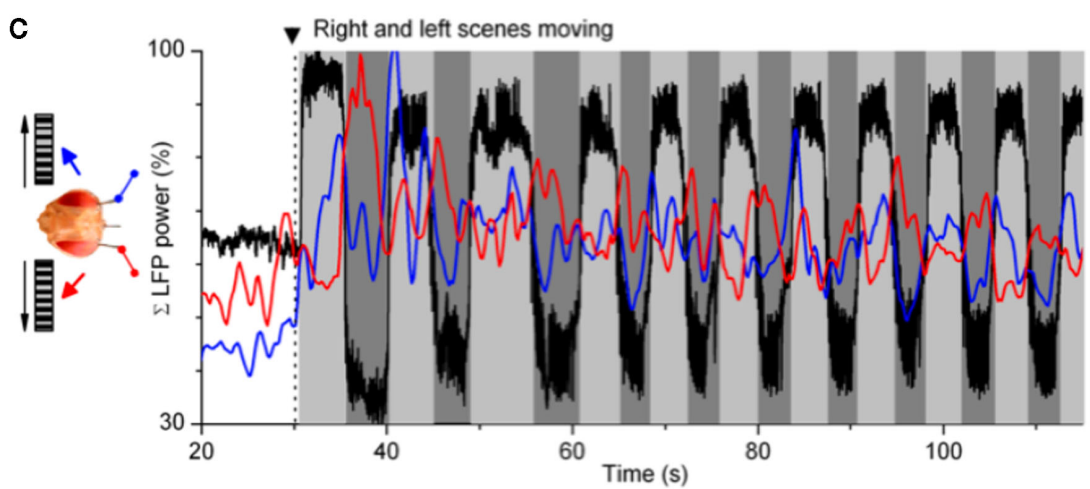

FIGURE 5 | Perceptual rivalry in Drosophila. (A) Original experiments by Heisenberg and Wolf (1984) showed that flies presented with two oscillating bars, one presented to either eye, would alternate their torque responses to either object (details in text). (B) Competing moving gratings presented to either eye of the fly also revealed alternating responses, rather than straight flight. (C) Recordings from the left and right brain of flies performing as in (B) revealed alternating local field potential (LFP) dynamics correlated with the behavioral switches. Black trace: torque behavior; red trace: left-brain LFP; blue trace: right-brain LFP. Figure reprinted from Tang and Juusola (2010). 
completely ignored optomotor flow from the contralateral side for seconds at a time. Fourth, flies alternated between the stimuli, and finally, flies displayed individual variability in their alternation dynamics. The stage was thus set to question whether flies were indeed attending to the competing gratings, and whether brain recordings might exhibit alternating activity that correlated with the behavioral choices (Figure 5C).

Behavior alone increases brain responses in flies. This was shown recently in two different studies in which Drosophila brain responses to moving gratings were boosted when the animals were actively walking (Seelig et al., 2010) or flying (Maimon et al., 2010). Tang and Juusola's (2010) recording preparation probed this effect further to ask how such boosted activity might be partitioned in the fly brain when the animals were making active behavioral choices to follow one or another competing visual stimulus. Two measures of brain activity were examined, LFPs and spikes. LFPs are voltage differentials between recording electrodes (in this case, between either optic lobe and a reference in the central brain), usually sampled around $500 \mathrm{~Hz}$. LFPs typically reveal oscillatory activity in brains, much like electroencephalograms taken from human scalps. Spikes, typically sampled above $25 \mathrm{KHz}$, represent single neuron firing. Typically, these are resolved as coming from single neurons (termed "units") by simultaneous recordings from multiple close wires (tetrodes). In Tang and Juusola's (2010) study, only one wire was implanted in each optic lobe, so spikes in that case most likely represent summed activity from multiple nearby action potentials. The study found that activity for both spikes and LFPs increased unilaterally, on the side associated with a behavioral choice (left or right). Although already a striking result, a closer examination of the LFP activity revealed even more interesting dynamics relevant to studies of rivalry. First, initial choices to fly left or right were preceded by a boosted LFP, sometimes by several hundred milliseconds. This effectively separated the behavior from brain activity, suggesting that the brain response might gate the behavior, and not vice versa. Second, when the fly alternated behavioral choices between the visual stimuli, LFP activity again predicted when a behavioral switch might happen. This was evidenced by calculating a ratio between LFP activity from either optic lobe, and plotting how LFP bias assigned to either hemisphere changed on average during a choice bout. Finally, the LFP frequencies found to be most increased during such alternating choice behavior were in the $20-50 \mathrm{~Hz}$ range, a frequency domain found previously in flies (Van Swinderen and Greenspan, 2003; Van Swinderen, 2007a; Van Swinderen et al., 2009) and other animals (e.g., Engel and Singer, 2001) to be involved in attention-like states.

The observation by Tang and Juusola (2010) that brain activity in the fly can precede and predict behavioral choices in a rivalry-like situation suggests that alternations in attention might exist independent of behavior, even in the small insect brain. Indeed, previous work in Drosophila has shown that 20-30 Hz LFP activity can be modulated by visual salience, even without associated behavioral responses, and that these LFP frequencies can be selected or suppressed in response to competing visual stimuli in classical conditioning or novelty paradigms (Van Swinderen and Greenspan, 2003; Van Swinderen, 2007a; Van Swinderen et al., 2009). In this slightly different recording preparation, tethered flies inside a drum of LEDs are exposed to moving stimuli rotating continuously around them (once every $3 \mathrm{~s}$ ) while LFPs are recorded from their brain (Figure 6A). Competing stimuli presented $180^{\circ}$ apart evoke $20-30 \mathrm{~Hz}$ responses when either object sweeps in front of the fly (Figure 6B); the objects are thus "tagged" by their timing on the rotating panorama. Interestingly, LFP responses to the competing stimuli are not stable through time when these are presented continuously to the fly for successive rotations. Instead, $20-30 \mathrm{~Hz}$ power assigned to one stimulus or the other may wax and wane during each successive presentation. Quantification of this process revealed $20-30 \mathrm{~Hz}$ alternation dynamics, where LFP activity would be increased for one object for multiple sweeps while activity was suppressed for the alternate object, and vice versa (Figures 6C,D). This dynamic appeared non-random in wild-type
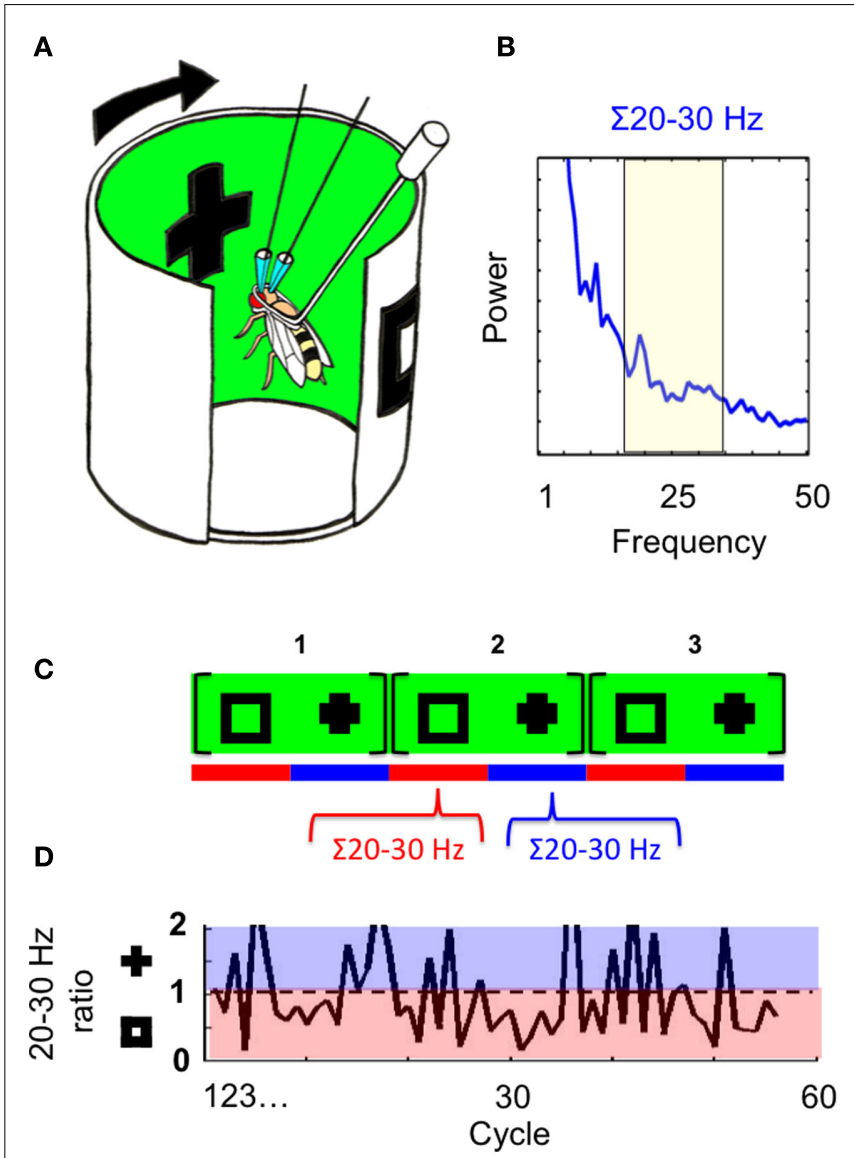

FIGURE 6 | Attention dynamics in the fly brain. (A) The recording arena. Flies are presented with moving visual stimuli displayed on a wrap-around LED screen. Two objects, a square and a cross, are displayed $180^{\circ}$ apart. (B) A spectral analysis of the flies' LFP in response to the moving visual stimuli, from 1 to $50 \mathrm{~Hz}$. The $20-30 \mathrm{~Hz}$ domain is selected for further analysis. (C) The cross and the square sweep recurrently in front of the fly every $3 \mathrm{~s}$ (every cycle). Twenty to $30 \mathrm{~Hz}$ responses are measured separately for each object sweep within a cycle (red and blue bars). (D) A ratio of the $20-30 \mathrm{~Hz}$ response evoked by either object is plotted, for each consecutive cycle. Ratios in the blue domain reveal increased responsiveness to the cross, and in the red domain show increased responsiveness to the square. Sixty cycles, or $180 \mathrm{~s}$ of data, are shown. Figures reprinted from Van Swinderen and Brembs (2010). 
flies (when compared to temporal permutations of the same LFP data), suggesting a persistence of attention-like responses assigned to either competing object (Van Swinderen, 2007b; Van Swinderen and Brembs, 2010).

A critical feature of Tang and Juusola's (2010) findings was their demonstration of alternating unilateral LFP activity during visual rivalry. In relation to this, they note the possibility that the fly brain spontaneously generates "rivalry between its left and right optic lobes by interhemispheric switching of their activity states" (p. 13). Tang and Juusola (2010) suggest this on the basis of their own electrophysiological data and a similar mechanistic model of rivalry in humans (Miller et al., 2000). The brain stimulation evidence garnered in support of the human interhemispheric switch model of rivalry, and the model's basis in the context of attentional selection, has been reviewed in detail elsewhere (Miller, 2001; Pettigrew, 2001; Miller and Ngo, 2007; Ngo et al., 2007, forthcoming). We do not here discuss in detail the issue of rivalry mechanisms (see Miller, forthcoming). These remain the subject of intense investigation and ongoing debate. Although there is agreement within the field that multiple levels of the visual hierarchy are involved, exactly what is rivaling at the neuronal population level in humans and other primates is still unknown.

It is debatable just how much support is provided by fly interhemispheric switch activity during rivalry, for the proposal that human rivalry is an interhemispheric switch phenomenon. After all, fly brains and human brains are substantially different (despite their similarities, as discussed above), with human brains possessing massive interhemispheric connections and discrete cortical area functional specialization. These and other differences may suggest an entirely different mechanism of competition in human and fly brains during rivalry. While this is certainly a possibility, we consider it remarkable that miniature brains demonstrate apparently higher-order cognitive phenomena such as selective attention and indeed, perceptual rivalry. It would not be that surprising therefore, in our view, if the fly brain's method of perceptual conflict resolution, involving switching between unihemispheric attentional selection mechanisms (Tang and Juusola, 2010), turns out to be one which human brains also employ (Miller, 2001). If so, this also suggests avenues for deciphering both the molecular mechanisms of slow rivalry rate in $\mathrm{BD}$ and the underlying pathophysiology of BD (Pettigrew and Miller, 1998; see below). Either way, although interhemispheric switching as a biological mechanism has been reported to mediate phenomena as diverse as sleep and birdsong (reviewed in Ngo et al., forthcoming), the data of Tang and Juusola (2010) are the first electrophysiological evidence to demonstrate such a mechanism can mediate perceptual rivalry.

\section{UTILIZING THE GENETIC WORKHORSE, DROSOPHILA}

Thus far, we have discussed the clinical relevance of rivalry rate differences, the relationship between attention and rivalry, and behavioral and electrophysiological properties of attentional switching in flies. In this section, we describe how the Drosophila rivalry model might be utilized to probe the genetic and molecular basis of individual variation in switch rate, as well as other applications relevant to clinical psychiatry. First however, it might be argued that more work needs to be done to establish that Drosophila switching behavior in the tethered flight arena is indeed rivalry. Tang and Juusola (2010) point out that conventional BR involves conflicting visual stimuli occupying overlapping regions of the visual field, which is not the case with their presentation of nonoverlapping monocular flow fields. Alternating torque responses might be reasonably considered evidence of alternating attentional selection (Heisenberg and Wolf, 1984; Maye et al., 2007), and indeed Tang and Juusola's (2010) recent electrophysiological work suggests further that this is in fact alternating unihemispheric attentional selection (interhemispheric switching). As discussed above, exactly such a process has been proposed to mediate rivalry in humans, although this is not yet conclusively established and it remains possible to question whether fly behavioral alternations indeed represent rivalry.

In our view however, we find it difficult to conceive of fly behavioral alternations as anything but rivalry, because the fundamental elements of rivalry phenomena are satisfied: the fly is presented with conflicting visual stimuli, albeit in non-overlapping visual field regions, and rather than respond in accordance with both sensory inputs (which it does however do some of the time, just as in human rivalry), it alternates between them with a period of seconds. The lack of overlapping visual fields with monocular flow stimuli in the tethered flight arena might indicate a difference from human BR, but human AFR similarly does not involve dichoptic presentation of field-overlapping stimuli, yet is quite clearly a form of perceptual rivalry. Indeed, AFR is a form of perceptual rivalry with many aspects in common with BR, including similar temporal properties, similar predominance modulation by activation of unilateral attentional structures, and similar slowing in BD. Perhaps not surprisingly therefore, fly behavioral switching has itself been reported in the context of visual figure-ground reversals (discussed above).

The path is open to now explore similarities and differences between fly and human visual rivalry. Most obvious would be exploration of temporal properties (alternation dynamics) of fly switching behavior, in terms of known human rivalry features, such as fit to a gamma distribution and other distributions (Brascamp et al., 2005), successive independence of phase durations (Fox and Herrmann, 1967), modulation of rate and predominance by stimulus strength parameters (Howard and Rogers, 2012), and within-subject rate reliability. Using more versatile LED arenas (Figure 6A), a host of other features of human rivalry could also be examined with respect to fly rivalry: selective versus non-selective suppression, involuntary attention effects, rapid eye-swap rivalry, interocular grouping (coherence) rivalry, perceptual and associative learning effects, priming and adaptation effects, onset rivalry, non-visual input and crossmodal effects on temporal dynamics, and perceptual stabilization with intermittent presentation. For all such phenomena to be examined, the fly model also enables assessment of individual variation therein (and its genetic basis), as well as their electrophysiological correlates. In addition, aspects of fly rivalry could be looked for in humans, including for example, neural activity that significantly precedes a perceptual switch. Indeed, such activity has recently been observed with human intracranial electrocorticogram recordings during rivalry (Tsuchiya et al., 2011). Brain-imaging and EEG in humans has also demonstrated with 
bistable motion rivalry and BR that right-sided cortical activation preceded transition-related activity, thus implicating these regions in the instigation of perceptual transitions (Sterzer and Kleinschmidt, 2007; Britz et al., 2011; cf. Knapen et al., 2011). Moreover, the fact that some degree of voluntary attention can be exerted on perception during human rivalry is also mirrored in the experiments by Tang and Juusola (2010), who consider that flies similarly have some degree of control over their torque switching behavior.

Most importantly however, Drosophila's propensity for genetic manipulation means it is an ideal animal model of human rivalry. Thus, not only can it be utilized to potentially progress understanding of the genetics of attention (Posner et al., 2007; Bellgrove and Mattingley, 2008), it also offers a unique opportunity to probe the genetic and molecular determinants of normal and pathophysiological variations of rivalry rate. That is, Drosophila mutants can be compared with wild-type flies to examine the effect of mutant genotypes on flight torque switch rate. Through understanding the molecular implications of Drosophila mutants that exhibit abnormal rivalry dynamics, the molecular basis of switch rate determination might be slowly unraveled. This approach in flies may further suggest candidate gene studies in humans, to again probe the molecular basis of rivalry rate variation. For studies of the genetic and molecular basis of $\mathrm{BD}$, this approach too may shed light. Thus postulates for the genetic basis of BD (e.g., Ferreira et al., 2008; Craddock and Sklar, 2009) can be examined by development of relevant Drosophila strains.

Although the tethered flight arena for Drosophila has provided the best insight to date on the possibility of perceptual rivalry in flies, it is less ideal for screening of genetic variants potentially useful for comparative studies with humans. Flies are tested one at a time in the arena - which is not conducive to large-scale screens - and the insects must fly for extended periods in order to report their perceptual choice dynamics, which is not guaranteed in mutant strains potentially burdened with pleiotropic defects. Thus, a dilemma presents itself, should we consider a Drosophila strategy to understanding perceptual rivalry: tethered, single fly assays are most revealing about rivalry, but least efficient for Drosophila genetic strategies. What are some possible strategies around this stumbling block?

The simplest solution is a brute force approach. The tethered flight arena is still amenable to genetic dissection; several studies have been published using this paradigm to test mutant strains and to dissect visual perception, learning, and saliency circuits in the Drosophila brain (Liu et al., 2006; Rister et al., 2007; Zhang et al., 2007; Pan et al., 2009). Provided that the mutants can fly sufficiently well, and that the questions asked are sufficiently narrow, the preparation does allow for genetic analysis. One drawback from being constrained to a narrow reverse-genetic strategy, however, is that little genetic exploration is possible along the lines of Seymour Benzer's original idea of uncovering new genes or circuits in an unbiased way. For example, almost all of the insight on visual learning in Drosophila has been an offshoot from olfactory learning studies, where the same genes or systems that were uncovered in olfactory learning screens were tested for visual learning. There is no strong reason to believe why these different memory systems (visual and olfactory) should be subserved by the same molecules or circuits in the fly brain, and indeed the evidence points to the contrary (Liu et al., 2006; Pan et al., 2009; Ofstad et al., 2011).

To get around the problem that the genetic variants need to fly, one solution is to screen by electrophysiology correlates alone. As we have seen above, the tethered non-flying fly still reveals attention-like responses in brain activity (Van Swinderen and Greenspan, 2003; Van Swinderen, 2007b) and these were found to alternate non-randomly in wild-type flies (Van Swinderen, 2007b; Van Swinderen and Brembs, 2010). Brain response dynamics to competing visual stimuli were altered in key variants, such as radish, a mutant that affects visual attention (Van Swinderen and Brembs, 2010). One could imagine a high-throughput electrophysiology paradigm where a succession of mutants are skewered with a multi-channel probe (as in Van Swinderen and Greenspan, 2003) to determine brain LFP dynamics in response to competing visual stimuli in an LED arena.

A simpler solution would be to utilize an alternative behavioral paradigm as a first-pass screen for rivalry phenotypes. The rate at which an animal may be switching its focus of attention may be difficult to quantify outside of tethered paradigms, but relatively easy to screen in population assays because of associated behavioral effects. The radish mutant in Drosophila is a case study in this regard. In brain-recording paradigms, radish mutants display random alternation dynamics in LFP responsiveness to competing visual stimuli, as discussed above. The same mutant displays a $1-2 \mathrm{~Hz}$ oscillation in activity at the torque meter, but only when presented with the competing visual stimuli (Van Swinderen and Brembs, 2010). Although both of these phenotypes (random $20-30 \mathrm{~Hz}$ dynamics in the brain and torque oscillations) are consistent with a perceptual rivalry defect, these phenotypes were not used to originally identify radish as a potential rivalry mutant. Rather, a high-throughput optomotor maze paradigm was used (Van Swinderen, 2007a; Van Swinderen and Flores, 2007). In this paradigm, populations of flies walk through eight consecutive choice points while they are exposed to moving gratings displayed on a computer monitor. A tendency to follow motion (the optomotor response) produces a bias in the distribution of flies at the end of the maze. This distribution bias was compromised in radish mutants, and further experiments adding competing visual stimuli to this paradigm revealed that the mutants were more distractible than wild-type flies (Van Swinderen and Brembs, 2010). Therefore, a simple and efficient behavioral assay such as the optomotor maze can be used to screen for potential rivalry phenotypes, producing candidates to be then tested more thoroughly in the arena or by electrophysiology. An automated and multiplexed version of the maze design (Evans et al., 2011) should allow for high-throughput screening of mutant strains potentially relevant to perceptual rivalry. In addition to providing an efficient platform for screening perceptual phenotypes, the visual maze design is also easily adapted to testing pharmacological influences on behavioral alternations. For example, radish mutant behavior in the maze was rescued from random alternations to significant optomotor responses by feeding flies methylphenidate (Van Swinderen and Brembs, 2010). A large-scale pharmacological screen of compounds that may influence perceptual alternations (e.g., psychotropic medications) would be easy to 
implement on this simple behavioral platform. Follow-up pharmacological studies could then also occur in the tethered flight arena.

Armed with the three different paradigms available to start screening for rivalry in flies (visual mazes, tethered flight, and electrophysiology), which mutants might be the most interesting to start with? Certainly, learning and memory mutants have a good chance of also being afflicted with defects in perceptual alternation dynamics. Indeed, many Drosophila learning and memory mutants have been found to also be defective in visual attention (Van Swinderen et al., 2009), providing promising candidates for further study in rivalry paradigms. On a broader scale, a variety of psychiatric disorders have been shown, albeit with less evidence than $\mathrm{BD}$, to exhibit switch rate anomalies, including attention deficit hyperactivity disorder (ADHD; fast with AFR; Gorenstein et al., 1989) and anxiety disorders (fast with AFR and BR; Meldman, 1965; Li et al., 2000; Nagamine et al., 2007). Genes associated with these disorders (and associated with $\mathrm{BD}$, as mentioned above) in humans might be screened in Drosophila mutants, first via a high-throughput visual maze paradigm, followed by tethered paradigms in select strains displaying aberrant phenotypes. The proof-of-principle for this approach is the recent radish mutant study in flies, where ADHD-like symptoms were suggested in a behavioral screen, confirmed by single fly behavior and electrophysiology, and then rescued by drug treatment (Van Swinderen and Brembs, 2010). Notably, this ADHD-like radish mutant was observed to perceptually switch at a fast rate, much like its human ADHD counterpart appears to do with AFR.

Knowing that we can test for rivalry-like effects in flies, some genes are clearly at the front of the line. For example, neuromodulators such as dopamine have been shown to modulate attention-like processes and arousal in flies (reviewed in Van Swinderen and Andretic, 2011). A likely connection between attention, reward systems or mood (discussed above), and rivalry rate make dopamine an excellent starting point for a deeper mechanistic understanding of perceptual rivalry in small brains (with noradrenaline implicated in human rivalry also; Einhäuser et al., 2008). Similarly, serotonin has been implicated in human visual rivalry (see above), mood and mood disorders, and hence variants in this neurotransmitter system can additionally be explored in the fly brain. Moreover, in relation to $\mathrm{BD}$, one particular Drosophila study that can be undertaken stems directly from Pettigrew and Miller's (1998) sticky switch model of this disorder. They proposed that the period of a seconds-long temporo-parietal interhemispheric switch (mediating BR) is genetically coupled to the period of a minutes-long prefrontal interhemispheric switch (related to cognitive style and mood), such that genetic slowing of one interhemispheric switch is, via pleiotropy, associated with slowing of the other. As a precedent for this proposed genetic coupling of different-period rhythms, it was noted that the same period gene mutation in Drosophila modulates both circadian rhythms (hours-long) and male courtship song cycles (minuteslong; Alt et al., 1998; Zordan et al., 2003). Thus the short per mutation is associated with short circadian and courtship cycles, and vice versa for the long per mutation. This line of reasoning can now be directly examined with respect to rivalry. A specific prediction can be made therefore, on the basis of the sticky switch model of $\mathrm{BD}$, that the short per mutant fly will exhibit a fast rate of torque flight behavior (for example), while the long per mutant, on the other hand, will exhibit a slow switch rate.

\section{ATTENTIONAL SELECTION AND NATURAL SELECTION}

Thus far, we have explored notions of attentional selection, suppression, and rivalry in humans and flies and outlined directions for future research to compare these processes in the two species and to understand the genetic basis of individual variation in human rivalry rate (and clinical anomalies therein). In what follows, we make some remarks about evolutionary aspects of attentional rivalry. We ask why there is rivalry at all, to what extent it is a ubiquitous feature of perception, how it may benefit or disadvantage an organism, and upon what aspects of the process natural selection acts.

First however, we note that two philosophical concepts have been applied to, and have benefited from, the study of perceptual phenomena - consciousness and free will. Consciousness is now widely regarded as a phenomenon (or group of phenomena, depending on one's definition) amenable to scientific investigation (Crick and Koch, 1998). Indeed, rivalry has proven one of the most useful tools in the scientific study of consciousness because it induces neural activity correlated with stimulus presentation that can be distinguished from neural activity correlated with stimulus perception (Logothetis, 1998). As useful as this approach is, the phenomenon of consciousness, and especially phenomenal consciousness (the subjective or experiential aspect), presents its own set of hard problems for science (Miller, 2007, forthcoming). These include locating the phenomenon in phylogeny and understanding what adaptive benefit, if any, there may be in an organism experiencing, rather than just behaving (as an automaton might). For such reasons, borrowing from notions of consciousness probably will not be a fruitful approach to addressing evolutionary aspects of rivalry. Adopting a different sense of "consciousness," in which the focus is not on experiential aspects but rather on perceptual content, or processes determining such content, may be more suited to evolutionary considerations. However, on this sense of "consciousness," the evolutionary issues seem just as effectively discussed by referring to notions of selection and suppression.

It is not clear whether the issue of free will, though of great philosophical and scientific interest in its own right (as for consciousness), will be informative for understanding evolutionary aspects of rivalry (despite the fact that this issue has recently been subjected to analysis in the context of the fly brain; Heisenberg, 2009; Brembs, 2011). As discussed above, though rivalry might be under some influence of voluntary attention, it is fundamentally an involuntary phenomenon involving alternate selection/suppression of conflicting stimuli, irrespective of the wants of the organism. It is of course, the needs of the organism that should be the focus of any evolutionary discussion. Why does an organism need the capacity to rival between alternative perceptions in situations in which more than one possibility exists? And if free will were to be relevant, at least in the sense of some degree of voluntary control over rivaling possibilities, why would an organism also need that capacity? 
In an evolutionary context, perceptual switching cannot be seen in isolation from its behavioral consequences. In some species, such as the sandlance with alternating oculomotor activity (Pettigrew et al., 1999), switching behavior appears to be a foraging and predator detection strategy to cover a wide region of space for potential food sources and potential predators, respectively. In species with binocular vision, rivalry may have evolved alongside the development of stereoscopic/depth perception, even though rivalry timing may reflect more fundamental processes already existing in simpler species requiring behavioral strategies for depth perception (e.g., saccadic "peering" in locusts and mantids; Kral and Poteser, 1997). Regarding perceptual rivalry (rather than oculomotor switching), it is not difficult to envisage that searching for food could benefit from rapid and flexible disambiguation of conflicting visual, auditory and olfactory stimuli (or from discriminating figure and ground, in the case of vision). Perceptual rivalry could similarly offer an efficient mechanism of predator detection in scenarios in which threats may be located in more than one region of space. Rivaling between existing or looming threat directions could maximize an organism's chances of successful escape, just as rivaling between existent or looming food sources could maximize chances of successful feeding.

Moreover, in both cases, some degree of voluntary control over the switching process (i.e., some degree of free will, though these phenomena are not necessarily equivalent - see Brembs, 2011) would be even more advantageous, by enabling further behavioral flexibility. On this account, it could be questioned why rivalry then is not an entirely voluntary phenomenon, as this could offer the most flexibility. However, an entirely voluntary strategy might also predispose an organism to taking too long to switch to an alternative threat or food source. This indeed raises the issue of rivalry timing, its genetic basis and the selective advantages or disadvantages of polymorphisms for these traits (fast versus slow switching, high versus low degree of voluntary control over the process). It is not difficult to grasp that switching too fast or too slowly could be disadvantageous in both food/prey and predator scenarios. Similarly, being unable to engage or disengage each alternative with appropriate flexibility could also be disadvantageous. The heritability of the degree of voluntary control over rivalry remains to be demonstrated, but as discussed above, heritability for individual variation in rivalry rate in humans has been established at around $50 \%$. The genes underlying such variation may well be those (along with their phenotypes) upon which selection has acted if indeed visual rivalry rate is reflective of evolutionarily ancient foraging and predator detection (attentional) switching mechanisms. In humans in particular, pleiotropy may also play a role in conferring selection pressures. Thus, genetic coupling of attentional switch dynamics to longer-period cognitive style interhemispheric rhythms may, according to Pettigrew and Miller's (1998) BD model, predispose individuals to becoming stuck in the leftapproach (manic) or right-withdrawal (depressed) state. These imbalanced states may in turn confer selective advantage (e.g., sexual disinhibition in mania, creativity in mania) or disadvantage (e.g., risk-taking in mania, social isolation in depression).

However, at the level of short-period attentional and perceptual switches, it is also possible that rivalry alternation dynamics - in humans or flies - may be tuned to the rate of change occurring in the environment, rather than to some intrinsic clock in the brain. This might make intuitive sense if rivalry were to have some adaptive function: one could imagine entirely different switch rates required for slow or fast-moving animals, or for animals in different environments. The concept of time for a fly must be completely different than that for a human, and perceptual alternation dynamics in the fly may be largely dependent on the rather artificial experimental set-up in tethered paradigms. An alternative view on the rivalry data would suggest that there does exist an endogenous switch in even simple brains that controls perceptual alternation dynamics. In flies, such switches have been identified for longer-term processes, such as those associated with circadian rhythms (as discussed above regarding the period gene), as well as for seconds-long processes in the fly brain (Rosay et al., 2001), so why not with shorter-term processes related to perception and attention? What experiments might one do in the fly to determine if an endogenous switch exists that controls perception in the seconds-long time scale?

To address whether flies make spontaneous decisions based upon an internal switch (rather than an external cue) is difficult, because one can never be entirely certain whether a cue was evident for the fly but not to the experimenter. An early paradigm tested Drosophila populations walking through a sequential choice maze, and found a reliable asymmetry in distributions of alternation behavior, inferred from their distributions at maze endpoints (Murphey, 1965). This suggested the presence of organismic bias in the direction of stereotypy: if flies turned right, they were more likely to turn right again at the following choice point, almost as if a left-right decision persisted across multiple choices, until an internally generated switch occurred. This observation of choice stereotypy was replicated several decades later in the eight-point visual choice maze (Van Swinderen and Flores, 2007), which was discussed in the previous section.

An even better paradigm for addressing spontaneous behavior in flies is again the tethered flight arena, but now in the absence of salient visual cues. As we have seen above, in the tethered paradigm, much like in a head-restrained monkey preparation, flies can still report choices while only seeing exactly what we want them to see - the ideal context for investigating rivalry. When placed in the context of an evenly illuminated white drum, the tethered fly presumably sees nothing but a field of white as it makes decisions on whether to fly straight or torque to the left or to the right. Even under these unchanging sensory conditions, choice behavior during long flights in the arena is highly variable (Maye et al., 2007). Rather than producing random distributions of torque behavior, flies display behaviors more resembling foraging behavior (Reynolds and Frye, 2007) such as fractal patterns or long-tailed Levy distributions. This suggests that non-random timing between choices is an intrinsic, adaptive trait even in the fly brain. Such endogenous control of alternations in animal brains might promote a level of perceptual exploration required for assigning salience to stimuli relevant to survival, when such an endogenous switch is directed to a succession of competing stimuli in the environment. In this sense, rivalry (choice alternation) mechanisms may shape behavior in much the same way that random mutations shape the evolution of a species. 
Reinhard Wolf and Martin Heisenberg, who performed the first fly rivalry experiments, described above, already proposed decades ago some parallels between spontaneous behavior in the brain and mutations in the evolution of a species. They stated:

As chance events, mutations and initiating acts have in common that the causes generating them often are biologically irrelevant, yet they become most important for the organism. The main point with initiation is not the existence of stochastic processes in the brain, but the existence of a type of stochastic process which is at the basis of behavioral adaptation in a manner quite analogous to Darwinian evolution. Thus, we expect initiation to be a highly organized affair.

(Heisenberg and Wolf, 1984, p. 222)

\section{CONCLUDING REMARKS}

Like the phenomenon itself, the focus of rivalry research has historically alternated, not just in terms of low- versus high-level mechanistic models, but also in terms of the field's interest in individual differences in rivalry parameters. We have discussed recent studies of rivalry rate differences in clinical and control populations and the new direction in rivalry research these perspectives represent. Thus, in addition to rivalry research benefiting from a combination of psychophysical and neuroscientific imag-

\section{REFERENCES}

Aafjes, M., Hueting, J. E., and Visser, P. (1966). Individual and interindividual differences in binocular retinal rivalry in man. Psychophysiology 3 , $18-22$.

Alais, D. (2012). Binocular rivalry: Competition and inhibition in visual perception. Wiley Interdiscip. Rev. Cogn. Sci. 3, 87-103.

Alais, D., van Boxtel, J. J., Parker, A., and van Ee, R. (2010). Attending to auditory signals slows visual alternations in binocular rivalry. Vision Res. 50, 929-935.

Alt, S., Ringo, J., Talyn, B., Bray, W., and Dowse, H. (1998). The period gene controls courtship song cycles in Drosophila melanogaster. Anim. Behav. 56, 87-97.

American Psychiatric Association. (2000). Diagnostic and Statistical Manual of Mental Disorders, 4th Edn. text rev, Washington, DC: American Psychiatric Association.

Bellen, H. J., Tong, C., and Tsuda, H. (2010). 100 years of Drosophila research and its impact on vertebrate neuroscience: a history lesson for the future. Nat. Rev. Neurosci. 11, 514-522.

Bellgrove, M. A., and Mattingley, J. B. (2008). Molecular genetics of attention. Ann. N. Y. Acad. Sci. 1129, 200-212.

Benzer, S. (1967). Behavioral mutants of Drosophila isolated by countercurrent distribution. Proc. Natl. Acad. Sci. U.S.A. 58, 1112-1119.
Blake, R. (1989). A neural theory of binocular rivalry. Psychol. Rev. 96, 145-167.

Blake, R. (2001). A primer on binocular rivalry, including current controversies. Brain Mind 2, 5-38.

Blake, R., and Logothetis, N. K. (2002). Visual competition. Nat. Rev. Neurosci. 3, 13-21.

Borsellino, A., de Marco, A., Allazetta, A., Rinesi, S., and Bartolini, B. (1972). Reversal time distribution in the perception of visual ambiguous stimuli. Kybernetik 10, 139-144.

Borst, A., Haag, J., and Reiff, D. F. (2010). Fly motion vision. Annu. Rev. Neurosci. 33, 49-70.

Brascamp, J. W., van Ee, R., Pestman, W. Distributions of alternation rates in various forms of bistable perception. J. Vis. 5, 287-298.

Breese, B. B. (1899). On inhibition. Psychol. Monogr. 3, 1-65.

Brembs, B. (2008). Operant learning of Drosophila at the torque meter. J. Vis. Exp. 16. e731, doi: 10.3791/731

Brembs, B. (2011). Towards a scientific concept of free will as a biological trait: spontaneous actions and decision-making in invertebrates. Proc. Biol. Sci. 278, 930-939.

Brembs, B., and Heisenberg, M. (2000). The operant and the classical in conditioned orientation of Drosophila melanogaster at the flight simulator. Learn. Mem. 7, 104-115.

Britz, J., Pitts, M. A., and Michel, C. M. (2011). Right parietal brain activity R., and van den Berg, A. V. (2005).

ing techniques, there is now reason to add to this interdisciplinary collaboration, clinical, genetic and molecular approaches. As well as having outlined various issues that are being examined currently and will require examination in the future, we have described in detail a model of perceptual rivalry in Drosophila, and its attentional basis, that may enable genetic and molecular dissection of (i) determinants of individual variation in rivalry rate, and (ii) clinically relevant rivalry variants. To this end, we have presented a specific research agenda utilizing this Drosophila model. Finally, we have begun discussion of evolutionary considerations relevant to attentional switch dynamics. Far from being just a source of amusement and intrigue, rivalry - and its examination in both large and miniature brains - may shed light on fundamental aspects of perception, attention, cognition and behavior, as well as human psychiatric disorders.

\section{ACKNOWLEDGMENTS}

Steven Mark Miller is supported by the Victoria Neurotrauma Initiative, the National Health and Medical Research Council (NHMRC) of Australia, and the Defence Health Foundation. Trung Thanh Ngo is supported by NHMRC (ID 490976). Bruno Van Swinderen is supported by an Australian Research Council Future Fellowship.

precedes perceptual alternation during binocular rivalry. Hum. Brain Mapp. 32, 1432-1442.

Carter, O., Konkle, T., Wang, Q., Hayward, V., and Moore, C. (2008). Tactile rivalry demonstrated with an ambiguous apparent-motion quartet. Curr. Biol. 18, 1050-1054.

Carter, O. L., Pettigrew, J. D., Hasler, F., Wallis, G. M., Liu, G. B., Hell, D., and Vollenweider, F. X. (2005). Modulating the rate and rhythmicity of perceptual rivalry alternations with the mixed 5HT2A and 5-HT1A agonist psilocybin. Neuropsychopharmacology 30 , 1154-1162.

Chong, S. C., and Blake, R. (2006) Exogenous attention and endogenous attention influence initial dominance in binocular rivalry. Vision Res. 46, 1794-1803.

Conrad, V., Bartels, A., Kleiner, M., and Noppeney, U. (2010). Audiovisual interactions in binocular rivalry. $J$. Vis. 10, 1-15.

Conus, P., and McGorry, P. D. (2002). First-episode mania: a neglected priority for early intervention. Aust. N. Z. J. Psychiatry 36, 158-172.

Craddock, N., and Sklar, P. (2009). Genetics of bipolar disorder: successful start to a long journey. Trends Genet. 25, 99-105.

Crain, K. (1961). Binocular rivalry: its relation to intelligence, and general theory of its nature and physiological correlates. J. Gen. Psychol. 64, 259-283.
Crick, F., and Koch, C. (1998). Consciousness and neuroscience. Cereb. Cortex 8, 97-107.

Dickinson, M. H., Lehmann, F. O., and Sane, S. P. (1999). Wing rotation and the aerodynamic basis of insect flight. Science 284, 1954-1960.

Einhäuser, W., Stout, J., Koch, C., and Carter, O. (2008). Pupil dilation reflects perceptual selection and predicts subsequent stability in perceptual rivalry. Proc. Natl. Acad. Sci. U.S.A. 105, 1704-1709.

Engel, A. K., and Singer, W. (2001). Temporal binding and the neural correlates of sensory awareness. Trends Cogn. Sci. (Regul. Ed.) 5, 16-25.

Enoksson, P. (1963). Binocular rivalry and monocular dominance studied with optokinetic nystagmus. Acta Ophthalmol. 41, 544-563.

Eriksen, C. W., and St James, J. D. (1986). Visual attention within and around the field of focal attention: a zoom lens model. Percept. Psychophys. 40, 225-240.

Evans, O., Paulk, A. C., and Van Swinderen, B. (2011). An automated paradigm for Drosophila visual psychophysics. PLoS ONE 6, e21619. doi:10.1371/journal.pone.0021619

Ewen, J. H. (1931). The psychological estimation of the effects of certain drugs upon the syntonic and schizophrenic psychoses. With a brief enquiry into a physiological basis of temperament. J. Ment. Sci. 77, 742-766. 
Fechner, G. T. (1860). Über einige Verhältnisse des binocularen Sehens. Leipzig: Hirzel.

Ferreira, M. A., O'Donovan, M. C., Meng, Y. A., Jones, I. R., Ruderfer, D. M., Jones, L., Fan, J., Kirov, G., Perlis, R. H., Green, E. K., Smoller, J. W., Grozeva, D., Stone, J., Nikolov, I., Chambert, K., Hamshere, M. L., Nimgaonkar, V. L., Moskvina, V., Thase, M. E., Caesar, S., Sachs, G. S., Franklin, J., Gordon-Smith, K., Ardlie, K. G., Gabriel, S. B., Fraser, C., Blumenstiel, B., Defelice, M., Breen, G., Gill, M., Morris, D. W., Elkin, A., Muir, W. J., McGhee, K. A., Williamson, R., MacIntyre, D. J., MacLean, A. W., St, C. D., Robinson, M., Van Beck, M., Pereira, A. C. P., Kandaswamy, R., McQuillin, A., Collier, D. A., Bass, N. J., Young, A. H., Lawrence, J., Ferrier, I. N., Anjorin, A., Farmer, A., Curtis, D., Scolnick, E. M., McGuffin, P., Daly, M. J., Corvin, A. P., Holmans, P. A., Blackwood, D. H., Wellcome Trust Case Control Consortium, Gurling, H. M., Owen, M. J., Purcell, S. M., Sklar, P., and Craddock, N. (2008). Collaborative genome-wide association analysis supports a role for ANK3 and CACNA1C in bipolar disorder. Nat. Genet. 40, 1056-1058.

Fox, R., and Check, R. (1968). Detection of motion during binocular rivalry suppression. J. Exp. Psychol. $78,388-395$

Fox, R., and Check, R. (1972). Independence between binocular rivalry suppression duration and magnitude of suppression. J. Exp. Psychol. 93, 283-289.

Fox, R., and Herrmann, J. (1967). Stochastic properties of binocular rivalry alternations. Percept. Psychophys. 2, 432-436.

Frederiksen, N. O., and Guilford, J. P. (1934). Personality traits and fluctuations of the outline cube. Am. J. Psychol. 46, 470-474.

George, R. W. (1936). The significance of the fluctuations experienced in observing ambiguous figures and in binocular rivalry. J. Gen. Psychol. 15, 39-61.

Gorenstein, E. E., Mammato, C. A., and Sandy, J. M. (1989). Performance of inattentive-overactive children on selected measures of prefrontaltype function. J. Clin. Psychol. 45, 619-632.

Gottesman, I. I., and Gould, T. D. (2003). The endophenotype concept in psychiatry: etymology and strategic intentions. Am. J. Psychiatry 160, 636-645.

Hancock, S., and Andrews, T. J. (2007). The role of voluntary and involuntary attention in selecting perceptual dominance during binocular rivalry. Perception 36, 288-298.

Heisenberg, M. (2009). Is free will an illusion? Nature 459, 164-165.

Heisenberg, M., and Wolf, R. (1984). Vision in Drosophila: Genetics of Microbehavior. Berlin: Springer-Verlag.

Hendricks, J. C., Finn, S. M., Panckeri, K. A., Chavkin, J., Williams, J. A., Sehgal, A., and Pack, A. I. (2000). Rest in Drosophila is a sleep-like state. Neuron 25, 129-138.

Hotta, Y., and Benzer, S. (1970). Genetic dissection of the Drosophila nervous system by means of mosaics. Proc. Natl. Acad. Sci. U.S.A. 67, 1156-1163.

Howard, I. P., and Rogers, B. J. (2012). Perceiving in Depth, Vol. 2, Stereoscopic Vision. New York: Oxford University Press.

Hunt, J., and Guilford, J. P. (1933). Fluctuation of an ambiguous figure in dementia praecox and in manicdepressive patients. J. Abnorm. Soc. Psychol. 27, 443-452.

Hupé, J.-M., Joffo, L. M., and Pressnitzer, D. (2008). Bistability for audiovisual stimuli: perceptual decision is modality specific. J. Vis. 8 , 1-15.

Hupé, J.-M., Lamirel, C., and Lorenceau, J. (2009). Pupil dynamics during bistable motion perception. J. Vis. 9, 1-19.

Itti, L., and Koch, C. (2000). A saliencybased search mechanism for overt and covert shifts of visual attention. Vision Res. 40, 1489-1506.

James, W. (1890). The Principles of Psychology. London: MacMillan.

Joyce, P. R. (1984). Age of onset in bipolar affective disorder and misdiagnosis as schizophrenia. Psychol. Med. 14, 145-149.

Kamphuisen, A. P., van Wezel, R. J. A., and van Ee, R. (2007). Interocular transfer of stimulus cueing in dominance selection at the onset of binocular rivalry. Vision Res. 47, 1142-1144.

Kendler, K. S., and Neale, M. C. (2010) Endophenotype: a conceptual analysis. Mol. Psychiatry 15, 789-797.

Knapen, T., Pearson, J., Brascamp, J., van Ee, R., and Blake, R. (2011). The role of frontal and parietal brain areas in bistable perception. J. Neurosci. 31, 10293-10301.

Kondo, H., Kitagawa, N., Kitamura, M., Koizumi, A., Nomura, M., and Kashino, M. (in press). Separability and commonality of auditory and visual bistable perception. Cereb. Cortex. doi:10.1093/cercor/bhr266
Kral, K., and Poteser, N. (1997). Motion parallax as a source of distance information in locusts and mantids. $J$. Insect Behav. 10, 145-163.

Krug, K., Brunskill, E., Scarna, A., Goodwin, G. M., and Parker, A. J. (2008). Perceptual switch rates with ambiguous structure-from-motion figures in bipolar disorder. Proc. Biol. Sci. $275,1839-1848$

LaBerge, D. (1983). Spatial extent of attention to letters and words. J. Exp. Psychol. Hum. Percept. Perform. 9, 371-379.

Lack, L. (1978). Selective Attention and the Control of Binocular Rivalry. Mouton: The Hague.

Lehmann, F. O., and Dickinson, M. H. (1997). The changes in power requirements and muscle efficiency during elevated force production in the fruit fly Drosophila melanogaster. J. Exp. Biol. 200, 1133-1143.

Leopold, D. A., and Logothetis, N. K. (1999). Multistable phenomena: changing views in perception. Trends Cogn. Sci. (Regul. Ed.) 3, 254-264.

Li, C.-S., Chen, M.-C., Yang, Y.-Y., Chang, H.-L., Liu, C.-Y., Shen, S. and Chen, C.-Y. (2000). Perceptual alternation in obsessive compulsive disorder - implications for a role of the cortico-striatal circuitry in mediating awareness. Behav. Brain Res. 111, 61-69.

Lichtenstein, P., Yip, B. H., Björk, C., Pawitan, Y., Cannon, T. D., Sullivan, P. F., and Hultman, C. M. (2009). Common genetic determinants of schizophrenia and bipolar disorder in Swedish families: a populationbased study. Lancet 373, 234-239.

Lin, Z., and He, S. (2009). Seeing the invisible: the scope and limits of unconscious processing in binocular rivalry. Prog. Neurobiol. 87, 195-211.

Liu, G., Seiler, H., Wen, A., Zars, T. Ito, K., Wolf, R., Heisenberg, M., and Liu, L. (2006). Distinct memory traces for two visual features in the Drosophila brain. Nature 439, 551-556.

Logothetis, N. K. (1998). Single units and conscious vision. Philos. Trans. R. Soc. Lond. B Biol. Sci. 353 1801-1818.

Long, G. M., and Toppino, T. C. (2004). Enduring interest in perceptual ambiguity: alternating views of reversible figures. Psychol. Bull. 130, 748-768.

Lumer, E. D., Friston, K. J., and Rees, G. (1998). Neural correlates of perceptual rivalry in the human brain. Science 280, 1930-1934.

Lunghi, C., Binda, P., and Morrone, M. C. (2010). Touch disambiguates rivalrous perception at early stages of visual analysis. Curr. Biol. 20, R143-R144.

Maimon, G., Straw, A. D., and Dickinson, M. H. (2010). Active flight increases the gain of visual motion processing in Drosophila. Nat. Neurosci. 13, 393-399.

Martin, L. F., Hall, M.-H., Ross, R. G., Zerbe, G., Freedman, R., and Olincy, A. (2007). Physiology of schizophrenia, bipolar disorder, and schizoaffective disorder. Am. J. Psychiatry 164, 1900-1906.

Maruya, K., Yang, E., and Blake, R. (2007). Voluntary action influences visual competition. Psychol. Sci. 18, 1090-1098

Masseck, O. A., and Hoffmann, K. P. (2009). Comparative neurobiology of the optokinetic reflex. Ann. N. Y. Acad. Sci. 1164, 430-439.

Maye, A., Hsieh, C. H., Sugihara, G., and Brembs, B. (2007). Order in spontaneous behavior. PLoS ONE 2, e443. doi:10.1371/journal.pone. 0000443

McDougall, W. (1906). III. Physiological factors of the attention-process (IV). Mind 15, 329-359.

Meldman, M. J. (1965). The quantitative analysis of anxiety and depression. Psychosomatics 6, 8-15.

Miller, S. M. (2001). Binocular rivalry and the cerebral hemispheres. With a note on the correlates and constitution of visual consciousness. Brain Mind 2, 119-149.

Miller, S. M. (2007). On the correlation/constitution distinction problem (and other hard problems) in the scientific study of consciousness. Acta Neuropsychiatr. 19, 159-176.

Miller, S. M., Gynther, B. D., Heslop, K. R., Liu, G. B., Mitchell, P. B., Ngo, T. T., Pettigrew, J. D., and Geffen, L. B. (2003). Slow binocular rivalry in bipolar disorder. Psychol. Med. 33, 683-692.

Miller, S. M., Hansell, N. K., Ngo, T. T., Liu, G. B., Pettigrew, J. D., Martin, N. G., and Wright, M. J. (2010). Genetic contribution to individual variation in binocular rivalry rate. Proc. Natl. Acad. Sci. U.S.A. 107, 2664-2668.

Miller, S. M., Liu, G. B., Ngo, T. T., Hooper, G., Riek, S., Carson, R. G., and Pettigrew, J. D. (2000). Interhemispheric switching mediates perceptual rivalry. Curr. Biol. 10 383-392.

Miller, S. M., and Ngo, T. T. (2007). Studies of caloric vestibular stimulation: implications for the cognitive neurosciences, the clinical neurosciences and neurophilosophy. Acto Neuropsychiatr. 19, 183-203.

Mitchell, J. F., Stoner, G. R., and Reynolds, J. H. (2004). Object-based attention determines dominance 
in binocular rivalry. Nature 429, 410-413.

Murphey, R. M. (1965). Sequential alternation behavior in the fruit fly, Drosophila melanogaster. J. Comp. Physiol. Psychol. 60, 196-199.

Nagamine, M., Yoshino, A., Miyazaki, M., Takahashi, Y., and Nomura, S. (2008). Effects of selective 5HT1A agonist tandospirone on the rate and rhythmicity of binocular rivalry. Psychopharmacology (Berl.) 198, 279-286.

Nagamine, M., Yoshino, A., Miyazaki, M., Takahashi, Y., and Nomura, S. (2009). Difference in binocular rivalry rate between patients with bipolar I and bipolar II disorders. Bipolar Disord. 11, 539-546.

Nagamine, M., Yoshino, A., Yamazaki, M., Obara, M., Sato, S., Takahashi, Y., and Nomura, S. (2007). Accelerated binocular rivalry with anxious personality. Physiol. Behav. 91, 161-165.

Ngo, T. T., Liu, G. B., Tilley, A. J., Pettigrew, J. D., and Miller, S. M. (2007). Caloric vestibular stimulation reveals discrete neural mechanisms for coherence rivalry and eye rivalry: a meta-rivalry model. Vision Res. 47, 2685-2699.

Ngo, T. T., Liu, G. B., Tilley, A. J., Pettigrew, J. D., and Miller, S. M. (2008). The changing face of perceptual rivalry. Brain Res. Bull. 75, 610-618.

Ngo, T. T., Mitchell, P. B., Martin, N. G., and Miller, S. M. (2011). Psychiatric and genetic studies of binocular rivalry: an endophenotype for bipolar disorder? Acta Neuropsychiatr. 23, 37-42.

Ofstad, T. A., Zuker, C. S., and Reiser, M. B. (2011). Visual place learning in Drosophila melanogaster. Nature 474, 204-207.

O’Kane, C. J. (2011). “Drosophila as a model organism for the study of neuropsychiatric disorders," in $\mathrm{Mol}$ ecular and Functional Models in Neuropsychiatry, ed. J. J. Hagan (Berlin: Springer-Verlag), 37-60.

Ooi, T. L., and He, Z. J. (1999). Binocular rivalry and visual awareness: the role of attention. Perception 28, 551-574.

Paffen, C. L. E., Alais, D., and Verstraten, F. A. J. (2006). Attention speeds binocular rivalry. Psychol. Sci. 17, 752-756.

Pan, Y., Zhou, Y., Guo, C., Gong, H., Gong, Z., and Liu, L. (2009). Differential roles of the fan-shaped body and the ellipsoid body in Drosophila visual pattern memory. Learn. Mem. 16, 289-295.

Pettigrew, J. D. (2001). Searching for the switch: neural bases for perceptual rivalry alternations. Brain Mind 2, 85-118.

Pettigrew, J. D., Collin, S. P., and Ott, M. (1999). Convergence of highlyspecialised behaviour, eye movements and visual optics in the sandlance (Teleostei) and the chameleon (Reptilia). Curr. Biol. 9, 421-424.

Pettigrew, J. D., and Miller, S. M. (1998). A "sticky" interhemispheric switch in bipolar disorder? Proc. Biol. Sci. 265, 2141-2148.

Posner, M. I., Rothbart, M. K., and Sheese, B. E. (2007). Attention genes. Dev. Sci. 10, 24-29.

Posner, M. I., Snyder, C. R., and Davidson, B. J. (1980). Attention and the detection of signals. J. Exp. Psychol. 109, 160-174.

Pressnitzer, D., and Hupé, J.-M. (2006). Temporal dynamics of auditory and visual bistability reveal common principles of perceptual organization. Curr. Biol. 16, 1351-1357.

Quinn, W. G., Harris, W. A., and Benzer, S. (1974). Conditioned behavior in Drosophila melanogaster. Proc. Natl. Acad. Sci. U.S.A. 71, 708-712.

Reynolds, A. M., and Frye, M. A. (2007). Free-flight odor tracking in Drosophila is consistent with an optimal intermittent scalefree search. PLoS ONE 2, e354. doi:10.1371/journal.pone.0000354

Rister, J., Pauls, D., Schnell, B., Ting, C. Y., Lee, C. H., Sinakevitch, I., Morante, J., Strausfeld, N. J., Ito, K., and Heisenberg, M. (2007). Dissection of the peripheral motion channel in the visual system of Drosophila melanogaster. Neuron 56, 155-170.

Rosay, P., Armstrong, J. D., Wang, Z., and Kaiser, K. (2001). Synchronized neural activity in the Drosophila memory centers and its modulation by amnesiac. Neuron 30, 759-770.

Sareen, P., Wolf, R., and Heisenberg, M. (2011). Attracting the attention of a fly. Proc. Natl. Acad. Sci. U.S.A. 108, 7230-7235.

Seedorff, H. H. (1956). Effect of alcohol on the motor fusion reserves and stereopsis as well as on the tendency to nystagmus. Acta Ophthalmol. 34, 273-280.

Seelig, J. D., Chiappe, M. E., Lott, G. K., Dutta, A., Osborne, J. E., Reiser, M. B., and Jayaraman, V. (2010). Twophoton calcium imaging from headfixed Drosophila during optomotor walking behavior. Nat. Methods 7, 535-540.

Shannon, R. W., Patrick, C. J., Jiang, Y., Bernat, E., and He, S. (2011). Genes contribute to the switching dynamics of bistable perception. J. Vis. 11, $1-7$.
Shaw, P. J., Cirelli, C., Greenspan, R. J., and Tononi, G. (2000). Correlates of sleep and waking in Drosophila melanogaster. Science 287, 1834-1837.

Sherman, A., and Dickinson, M. H. (2003). A comparison of visual and haltere-mediated equilibrium reflexes in the fruit fly Drosophila melanogaster. J. Exp. Biol. 206, 295-302.

Sherrington, C. S. (1906). Integrative Action of the Nervous System. New Haven: Yale University Press.

Smoller, J. W., and Finn, C. T. (2003). Family, twin, and adoption studies of bipolar disorder. Am. J. Med. Genet. C Semin. Med. Genet. 123C, 48-58.

Srinivasan, M. V., Poteser, M., and Kral, K. (1999). Motion detection in insect orientation and navigation. Vision Res. 39, 2749-2766.

Sterzer, P., and Kleinschmidt, A. (2007). A neural basis for inference in perceptual ambiguity. Proc. Natl. Acad. Sci. U.S.A. 104, 323-328.

Stoner, G. R., Mitchell, J. F., Fallah, M., and Reynolds, J. H. (2005). Interacting competitive selection in attention and binocular rivalry. Prog. Brain Res. 149, 227-234.

Tammero, L. F., and Dickinson, M. H. (2002). Collision-avoidance and landing responses are mediated by separate pathways in the fruit fly, Drosophila melanogaster. J. Exp. Biol. 205, 2785-2798.

Tang, S., and Juusola, M. (2010). Intrinsic activity in the fly brain gates visual information during behavioral choices. PLOS ONE 5, e14455. doi: 10.1371/journal.pone. 0014455

Treisman, A. M., and Gelade, G. (1980). A feature-integration theory of attention. Cogn. Psychol. 12, 97-136.

Tsuchiya, N., Chung, J., Eliashiv, D. Adolphs, R., and Mamelak, A. (2011).Visual consciousness tracked with direct intracranial recording from early visual cortex in humans. Nat. Preced. http://dx.doi.org/10. 1038/npre.2011.6040.1

Tsuchiya, N., and Koch, C. (2005). Continuous flash suppression reduces negative afterimages. Nat. Neurosci. 8, 1096-1101.

Valentin, G. (1844). Lehrbuch der Physiologie des Menschen: für Ärzte und Studirende, Vol. 2. Brunswick.

van Dam, L. C. J., and van Ee, R. (2006). Retinal image shifts, but not eye movements per se, cause alternations in awareness during binocular rivalry. J. Vis. 6, 1172-1179. van Ee, R., van Boxtel, J. J., Parker, A. L., and Alais, D. (2009). Multisensory congruency as a mechanism for attentional control over perceptual selection. J. Neurosci. 29, 11641-11649.

Van Swinderen, B. (2005). The remote roots of consciousness in fruitfly selective attention? Bioessays 27, 321-330.

Van Swinderen, B. (2007a). Attentionlike processes in Drosophila require short-term memory genes. Science 315, 1590-1593.

Van Swinderen, B. (2007b). The attention span of a fly. Fly (Austin) 1, 187-189.

Van Swinderen, B., and Andretic, R. (2011). Dopamine in Drosophila: setting arousal thresholds in a miniature brain. Proc. Biol. Sci. 278, 906-913.

Van Swinderen, B., and Brembs, B. (2010). Attention-like deficit and hyperactivity in a Drosophila memory mutant. J. Neurosci. 30, 1003-1014.

Van Swinderen, B., and Flores, K. A. (2007). Attention-like processes underlying optomotor performance in a Drosophila choice maze. J. Neurobiol. 67, 129-145.

Van Swinderen, B., and Greenspan, R. J. (2003). Salience modulates 20-30 $\mathrm{Hz}$ brain activity in Drosophila. Nat. Neurosci. 6, 579-586.

Van Swinderen, B., McCartney, A., Kauffman, S., Flores, K., Agrawal, K., Wagner, J., and Paulk, A. (2009). Shared visual attention and memory systems in the Drosophila brain. PLoS ONE 4, e5989. doi:10.1371/journal.pone.0005989

Von Helmholtz, H. L. F. (1867). Handbuch der Physiologischen Optik. Leipzig: Voss.

Vosshall, L. B. (2007). Into the mind of a fly. Nature 450, 193-197.

Wales, R., and Fox, R. (1970). Increment detection thresholds during binocular rivalry suppression. Percept. Psychophys. 8, 90-94.

Walker, P. (1978). Binocular rivalry: central or peripheral selective processes? Psychol. Bull. 5, 376-389.

Wallace, B., and Priebe, F. A. (1985). Hypnotic susceptibility, interference and alternation frequency to the Necker cube illusion. J. Gen. Psychol. 112, 271-277.

Watanabe, M., Cheng, K., Murayama, Y., Ueno, K., Asamizuya, T., Tanaka, K., and Logothetis, N. (2011). Attention but not awareness modulates the BOLD signal in the human V1 during binocular suppression. Science 334, 829-831. 
Wheatstone, C. (1852). The Bakerian lecture: contributions to the physiology of vision part the second. On some remarkable, and hitherto unobserved, phenomena of binocular vision (continued). Philos. Trans. R. Soc. Lond. 142, 1-17.

Wolf, R., and Heisenberg, M. (1991). Basic organization of operant behavior as revealed in Drosophila flight orientation. J. Comp. Physiol. A. 169, 699-705.

Zhang, K., Guo, J. Z., Peng, Y., Xi, W., and Guo, A. (2007).
Dopamine-mushroom body circuit regulates saliency-based decisionmaking in Drosophila. Science 316, 1901-1904.

Zhang, P., Jamison, K., Engel, S., He, B., and He, S. (2011). Binocular rivalry requires visual attention. Neuron 71 , 362-369.

Zhou, W., Jiang, Y., He, S., and Chen, D. (2010). Olfaction modulates visual perception in binocular rivalry. Curr. Biol. 20, 1356-1358.

Zordan, M., Sandrelli, F., and Costa, R. (2003). A concise overview of circadian timing in Drosophila. Front. Biosci. 8, d870-d877.

Conflict of Interest Statement: Steven Mark Miller is a co-inventor on granted University of Queensland, national, and international patents concerning slow binocular rivalry in bipolar disorder. There are currently no commercialization activities.

Received: 01 September 2011; accepted 23 December 2011; published online: 18 January 2012.
Citation: Miller SM, Ngo TT and van Swinderen B (2012) Attentional switching in humans and flies: rivalry in large and miniature brains. Front. Hum. Neurosci. 5:188. doi: 10.3389/fnhum.2011.00188

Copyright (c) 2012 Miller, Ngo and van Swinderen. This is an open-access article distributed under the terms of the Creative Commons Attribution Non Commercial License, which permits noncommercial use, distribution, and reproduction in other forums, provided the original authors and source are credited. 